\title{
An ionic control of metabolic-epigenetic reprogramming links inflammation to membrane potential-mediated nutrient acquisition
}

Di Wang ( $\sim$ diwang@zju.edu.cn )

Zhejiang University

Weiwei Yu

Zhejiang University

Zhen Wang

Zhejiang University

Xiafei Yu

Zhejiang University

Zhexu Chi

Zhejiang University

Kailian Zhang

Zhejiang University

\section{Sheng Chen}

Zhejiang University

\section{Ting Xu}

Zhejiang University

Danlu Jiang

Zhejiang University

Xingchen Guo

Zhejiang University

Mobai Li

Zhejiang University

Jian Zhang

Zhejiang University

Hui Fang

Zhejiang University

Qizhen Ye

Zhejiang University

Xuyan Yang

Zhejiang University

Xue Zhang 
Department of Pathology and Pathophysiology,Zhejiang University School of Medicine

\section{Yingliang Wu}

Wuhan University

Wei Yang

Zhejiang University

\section{Article}

Keywords: metabolic-epigenetic reprogramming, inflammation, ionic control

Posted Date: October 9th, 2020

DOI: https://doi.org/10.21203/rs.3.rs-85111/v1

License: (c) (i) This work is licensed under a Creative Commons Attribution 4.0 International License. Read Full License 


\section{Abstract}

Metabolic and epigenetic reprogramming play pivotal roles in driving inflammation, but the precise regulatory mechanisms remain minimally understood. Here we show an ionic control mediated by macrophage Kir2.1, an inwardly-rectifying K+ channel, promting lipopolysaccharide (LPS)-induced inflammation. Kir2.1 blockade by the selective inhibitor ML133 or its specific deletion in macrophages suppressed the production of LPS-induced inflammatory factors, such as interleukin-1 $\beta$, and protected mice from LPS-induced sepsis in vivo. Kir2.1 loss-of-function led to a nutrient starvation phenotype, with impaired glucose and serine-glycine-one-carbon metabolism, whose synergy promotes the generation of S-adenosylmethionine (SAM). Accordingly, reduced SAM availability by Kir2.1 blockade decreased histone methylation at key inflammatory effector loci, such as $\| 1 \mathrm{~b}$. Although the immunomodulatory effect of Kir2.1 was independent of modulation by $\mathrm{Ca} 2+$ flux and general signaling pathways, its loss-offunction led to a depolarized membrane potential $(\mathrm{Vm})$ which decreased the surface expression of nutrient transporters, including GLUT1 and CD98. We thus identify an ionic control of metabolicepigenetic reprogramming that links inflammation to $\mathrm{Vm}$-mediated nutrient acquisition and identifies potential new strategies for anti-inflammatory therapy.

\section{Introduction}

Macrophage activation by Toll-like receptors, notably Toll-like receptor 4 (TLR4), is intrinsically linked to metabolic reprogramming. Upon lipopolysaccharide (LPS) stimulation, inflammatory macrophages require a profound reprogramming of cellular metabolism to meet their metabolic demands for performing diverse inflammatory functions including the production and secretion of inflammatory cytokines. For example, LPS stimulation results in an increase in glycolytic activity and enhanced cellular anabolism to support inflammatory activity (O'Neill et al., 2016). The glycolytic enzyme pyruvate kinase M2 and the tricarboxylic acid (TCA) cycle metabolite succinate have been shown to induce pro-IL-1 $\beta$ expression through hypoxia-inducible factor 1-alpha activity (Palsson-McDermott et al., 2015a; Tannahill et al., 2013). Another TCA cycle metabolite, itaconate, acts as an anti-inflammatory metabolite via nuclear factor erythroid 2-related factor 2 (Mills et al., 2018). In addition, we have previously demonstrated that LPS activates the pentose phosphate pathway, the serine synthesis pathway, and one-carbon metabolism, the synergism of which drives epigenetic reprogramming for interleukin-1 $\beta$ (IL-1 $\beta$ ) expression (Yu et al., 2019). However, how inflammatory macrophage metabolic phenotypes reflect biochemical dependencies and how the nutrient availability orchestrates inflammatory responses are still elusive.

In contrast to rapidly-proliferating cells, macrophages are not prone to rapid proliferation after LPS stimulation, but instead produce diverse inflammatory cytokines (O'Neill et al., 2016). However, macrophages still require a constant supply of extracellular nutrients that fuel both anabolic metabolism and the synthesis of diverse inflammatory factors. To acquire extracellular nutrients such as glucose and amino acids, cells including macrophages rely on transporter proteins in the plasma membrane (McCracken and Edinger, 2013). For example, glucose transporter 1 (GLUT1)-mediated glucose 
metabolism plays critical roles in driving inflammatory macrophages (Freemerman et al., 2014). Although the alterations of cellular metabolic landscape upon LPS stimulation has been gradually illustrated, the regulatory mechanisms that maintain the nutrient acquisition to meet the metabolic demands for inflammation are minimally understood, particularly how macrophages coordinate different environmental changes (such as changes in ions and $\mathrm{pH}$ ) to dynamically acquire and exploit extracellular nutrients for driving inflammation.

Many lines of investigation have demonstrated that intact ion transport is required for both innate and adaptive immunity. In immune cells, divalent cations such as $\mathrm{Ca}^{2+}, \mathrm{Mg}^{2+}$, and $\mathrm{Zn}^{2+}$ are important as second messengers to regulate immune signaling pathways. By contrast, monovalent cations such as $\mathrm{K}^{+}$ and $\mathrm{Na}^{+}$are mainly required for the regulation of membrane potential $\left(\mathrm{V}_{\mathrm{m}}\right)$, which indirectly controls $\mathrm{Ca}^{2+}$ flux and immune cell signaling (Feske et al., 2015). Studies using patch-clamp recording have revealed that macrophages express several types of $\mathrm{K}^{+}$channel required for $\mathrm{K}^{+}$homeostasis, $\mathrm{V}_{\mathrm{m}}$, and $\mathrm{Ca}^{2+}$ dependent signaling pathways during inflammation (Feske et al., 2015). For example, the voltage-gated $\mathrm{K}_{\mathrm{V}} 1.3$ channel is critical for setting the resting $\mathrm{V}_{\mathrm{m}}$ in macrophages (Mackenzie et al., 2003), and promotes the proliferation and inducible nitric oxide synthase expression stimulated by macrophage colonystimulating factor (Vicente et al., 2003). Another $\mathrm{K}^{+}$channel, $\mathrm{K}_{\mathrm{Ca}} 3.1$, is activated by $\mathrm{Ca}^{2+}$ influx and is required for MCP-1-mediated macrophage migration into inflamed tissues (Toyama et al., 2008). Recently, the two-pore-domain $\mathrm{K}^{+}$channels TWIK2 and THIK1 have been demonstrated to activate NLRP3 inflammasome by mediating $\mathrm{K}^{+}$efflux (Di et al., 2018; Madry et al., 2018). However, despite the surging interest in the role of metabolic reprogramming in driving inflammatory macrophages, little attention has been paid to the ionic control of nutrient access and utilization during inflammation.

Here we found the inward rectifier $\mathrm{K}^{+}$channel, Kir2.1, was essential for the production of LPS-induced inflammatory effectors such as IL-1 $\beta$ by promoting nutrient import and utilization. Blockade of Kir2.1 impaired glucose and serine-glycine-one-carbon (SGOC) metabolism, whose synergy fuels histone methylation for the expression of LPS-induced inflammatory genes by supporting the generation of Sadenosylmethionine (SAM). We also uncovered an unexpected mechanism by which Kir2.1-mediated regulation of $\mathrm{V}_{\mathrm{m}}$ maintains surface nutrient transporters levels to meet the metabolic demands of inflammatory macrophages. Thus, we identify an ionic-metabolic-epigenetic axis that links inflammation to nutrient acquisition and provide potential new strategies of manipulating $V_{m}$ for anti-inflammatory therapy.

\section{Results}

\section{Kir2.1 is highly expressed and regulates the membrane potential in primary macrophages}


Using RNA-sequencing (RNA-seq) analysis, we found that $\mathrm{K}_{\mathrm{Ca}} 3.1$ (encoded by Kcnn4), THIK1 (encoded by Kcnk13), TWIK2 (encoded by Kcnk6), and Kir2.1 (encoded by Kcnj2) were most strongly expressed in bone-marrow-derived macrophages (BMDMs) (Fig. $1 \mathrm{~A}) . \mathrm{K}_{\mathrm{Ca}} 3.1$ plays a role in macrophage activation and migration (Feske et al., 2015), while TWIK2 and THIK1 have recently been shown to be required for NLRP3 inflammasome activation by promoting $\mathrm{K}^{+}$efflux (Di et al., 2018; Madry et al., 2018). We thus focused on the inwardly-rectifying $\mathrm{K}^{+}$channel Kir2.1. Under physiological conditions, Kir channels generate a large $\mathrm{K}^{+}$ conductance at potentials negative to $\mathrm{K}^{+}$equilibrium potential $\left(\mathrm{E}_{\mathrm{K}}\right)$ but also permit a relatively small current flow at potentials slightly more positive to $E_{K}$ which is essential to stabilize the resting membrane potential $\left(V_{m}\right)$ (Hibino et al., 2010; Miyazaki et al., 1974; Sakmann and Trube, 1984). Among different tissues and cell types, the expression of Kir2.1 was relatively high in macrophages and other specialized macrophages including osteoclasts and microglia (Figure S1A). To examine whether primary macrophages exhibit functional Kir2.1 channels, we performed whole-cell patch-clamp recordings from peritoneal macrophages subjected to voltage-ramps from -120 to $+60 \mathrm{mV}$. Ba ${ }^{2+}\left(\mathrm{BaCl}_{2}\right)$ is usually used to block the Kir channels and we found a robust $\mathrm{Ba}^{2+}$-sensitive Kir current in the current-voltage relationship (Figure S1B). ML133 is a selective Kir2 blocker, with an IC ${ }_{50}$ of $1.9 \mu \mathrm{M}$ for Kir2.1 (Wang et al., 2011; Wu et al., 2010). In HEK293 cells transfected with Kir2.1, ML133 potently inhibited the Kir2.1 current of both a large inward current component and a slight outward current component (Edwards and Hirst, 1988; Sakmann and Trube, 1984) (Figure S1C). Consistently, ML133 inhibited the endogenous Kir2.1 currents in both resting and LPS-stimulated peritoneal macrophages (Figs. 1B, 1C, 1F, and S1D).

Because knockout of Kir2.1 is lethal in the neonate (Zaritsky et al., 2000), its role in immune cells has not been reported using Kir2.1-deficient immune cells. We deleted Kir2.1 selectively in myeloid cells by generating $L y z 2-c r e-K c n j 2^{f / f}$ mice and found the ability of bone marrow cells to differentiate ex vivo into macrophages in the absence of Kir2.1 was normal in light of the expression of the macrophage surface markers CD11b and F4/80 (Figure S1F). The proliferation of cultured Kir2.1-deficient BMDMs was also normal (Figure S1G). However, Kir2.1 deficiency greatly impaired the Kir2.1 currents in both resting and LPS-stimulated peritoneal macrophages (Figs. 1D, 1E, 1F, and S1E), and ML133 showed no additional effect (Figs. 1D, 1E, and 1F).

Kir2.1 was reported to stabilize the resting $V_{m}$ of many cell types including cardiac myocytes (Sakmann and Trube, 1984), vascular smooth muscle cells (Karkanis et al., 2003; Park et al., 2008; Quayle et al., 1993), endothelial progenitor cells (Quayle et al., 1993; Zhang et al., 2019) and microglial cells (Gattlen et al., 2020). We first adopted a real-time dynamic detection of peritoneal macrophage $V_{m}$ for 3 min by patch clamp experiments because of a relatively slow inhibitory effect of ML133 on Kir2.1 (Figs. 1B and 1C). The $V_{m}$ of peritoneal macrophages $(-38.4 \pm 2.8 \mathrm{mV})$ was not changed when Kir2.1 was blocked by ML133 (-39.4 $\pm 3.4 \mathrm{mV})$ in the resting state. However, the $V_{m}$ of LPS-stimulated macrophages was dramatically changed from $-42.8 \pm 2.9 \mathrm{mV}$ to a much more depolarized $\mathrm{V}_{\mathrm{m}}$ of $+12.3 \pm 1.9 \mathrm{mV}$ by ML133, and to a lesser extent, to $-29.7 \pm 2.3 \mathrm{mV}$ due to Kir2.1 deficiency (Figs. $1 \mathrm{G}$ and $\mathrm{S} 1 \mathrm{H}$ ). Moreover, the effect of ML133 was abolished in Kir2.1-deficient macrophages (Figs. 1G and S1H), further indicating the 
specificity of ML133 on Kir2.1. We also performed patch clamp recording for a short period of time of 30 seconds and found the $V_{m}$ of LPS-stimulated macrophages $(-31.9 \pm 1.6 \mathrm{mV})$ was depolarized to $-17.3 \pm$ $1.1 \mathrm{mV}$ due to Kir2.1 deficiency (Fig. $1 \mathrm{H})$. Of note, the $\mathrm{V}_{\mathrm{m}}$ of resting macrophages was also depolarized by Kir2.1 deficiency under this condition (Fig. 1H), suggesting a discrepancy in the depolarization of resting macrophages between ML133 (acute blockade) and Kir2.1 deficiency (long-term absence). Together, we conclude that Kir2.1 plays a critical role in regulating the membrane potential of inflammatory macrophages.

\section{Kir2.1 loss-of-function suppresses LPS- and infection- induced inflammatory cytokines and pathological inflammation}

To explore the role of Kir2.1 in LPS-induced inflammation, we first treated LPS-stimulated peritoneal macrophages with ML133 and found little cytotoxicity of ML133 (Figure S2A). Strikingly, ML133 dosedependently inhibited the LPS-induced IL-1 $\beta$, but not the TNF- $a$ (Figs. 2A and 2B). Blockade of Kir2.1 by $\mathrm{Ba}^{2+}$ gave similar results (Figure S2B). To more broadly explore the effect of ML133, we performed RNAseq analysis in BMDMs and found that, while $/ / 1 \mathrm{~b}$ was the gene most decreased by ML133, a cluster of LPS-induced inflammatory genes including $/ / 1 a,\|/ 18\|$,$12 a , and / / 6$ were also decreased, but Tnf was still not affected (Figs. 2C and S2C). Gene set enrichment analysis (GSEA) of the RNA-seq data showed a striking enrichment of 'inflammatory response' after ML133 treatment (Fig. 2D). Next, we used several genetic strategies to further investigate the role of Kir2.1 in LPS-induced inflammation. Silencing of Kcnj2 by small-interfering RNAs (siRNAs) in BMDMs or stably expressing shRNAs in immortalized BMDMs (iBMDMs) suppressed the LPS-induced IL-1 $\beta$, but not the TNF-a (Figures S2D-S2G). Peritoneal macrophages from $L y z 2-c r e-K c n j 2^{f / f}$ mice similarly showed a reduction in LPS-induced IL-1 $\beta$ compared to wild-type mice (Fig. 2E). We also treated Kir2.1-depleted peritoneal macrophages with ML133 and found the inhibitory effect of ML133 on LPS-induced IL-1 $a$ and IL-1 $\beta$ was greatly impaired, further suggesting the specificity of ML133 through Kir2.1 (Figures S2H). To address the function of Kir2.1 in vivo, we used an LPS-induced sepsis model which largely reflects the inflammatory functions of monocytes/macrophages. ML133 or Kir2.1 deficiency significantly decreased the serum levels of IL-1 $\beta$ and increased the survival of mice (Figs. 2F-2I). The decreased TNF-a levels in $L y z 2-c r e-K c n j 2^{f / f}$ mice are probably due to the contribution of IL-1 $\beta$ to TNF-a production in vivo (Fig. 2H) (Tannahill et al., 2013). When infected with Gram-negative bacteria, such as Escherichia coli and S. typhimurium (strain SL1344), ML133 or Kir2.1 deficiency similarly led to decreased IL-1 $\beta$ and IL-1 a production both in vitro and in vivo, with less effect on the TNF-a (Figs. 2J, 2K, S2I, and S2J). Last, to strengthen the evidence for an antiinflammatory effect of Kir2.1 blockade in samples from patients, we used synovial fluid cells from gouty patients. Gout is an inflammatory form of arthritis and IL-1 inhibitors are effective in treating patients with acute and chronic gout (Jiang et al., 2017). We found that ML133 prevented IL-1 $\beta$ production in freshly-isolated synovial fluid cells from gouty patients (Fig. 2L). These data together indicate that Kir2.1 stimulates LPS-induced inflammation and reveal a potential anti-inflammatory strategy by targeting Kir2.1. 


\section{Kir2.1 promotes LPS-induced glucose uptake and consumption in inflammatory macrophages}

Given the inconsistent inhibition of LPS-induced IL-1 $\beta$ and TNF- $a$, we predicted that Kir2.1 blockade would not affect the general signaling pathways mediated by TLR4, including the NF-KB and MAPK activation essential for both cytokines upon LPS stimulation. As predicted, ML133 or Kir2.1 deficiency had little effect on LPS-induced NF-KB and MAPK activation (Figures S3A-S3C). Accumulating evidence indicates that the Warburg effect of aerobic glycolysis plays critical roles in driving inflammatory macrophages, in particular the LPS-induced IL-1 $\beta$ production (Adamik et al., 2013; O'Neill et al., 2016). We thus further investigated whether Kir2.1 drives inflammatory macrophages by modulating LPS-induced metabolic reprogramming. We first measured real-time changes in the extracellular acidification rate (ECAR) and found ML133 or Kir2.1 deficiency led to a decrease in the LPS-induced long-term commitment to glycolysis (Fig. 3A). Moreover, both unbiased metabolomics profiling and a targeted metabolomics approach revealed that ML133 decreased the LPS-induced accumulation of metabolites representing aerobic glycolysis (Figs. 3B and 3C), suggesting a role of Kir2.1 in supporting a constant glycolysis during inflammation. Akt-mTORC1 signaling and HIF-1a activation were reported to modulate LPS-induced aerobic glycolysis and IL-1 $\beta$ production (Everts et al., 2014; Mills et al., 2016; Mills et al., 2018; Palsson-McDermott et al., 2015b; Tannahill et al., 2013). We found ML133 or Kir2.1 depletion had little effect on the early LPS induction of Akt-mTORC1 signaling in light of the phosphorylation of Akt and S6 (Figures S3A, S3B, and S3D). Moreover, GSEA of RNA-seq data showed that 'mTORC1 signaling' and 'HIF-1a targets' were not particularly enriched by ML133 (Figures S3E and S3F). Given that macrophages require a constant supply of extracellular glucose to support their intracellular metabolic reprogramming (Freemerman et al., 2014; Gamelli et al., 1996), we next considered the possibility that Kir2.1 promotes glucose import during LPS stimulation. Strikingly, LPS-induced glucose uptake in peritoneal macrophages was dose-dependently inhibited by ML133 in vitro (Fig. 3D). Similar results were obtained in peritoneal macrophages from $L y z 2-c r e-K c n j 2^{f / f}$ mice compared to wild-type macrophages (Fig. 3E). Furthermore, we assessed this effect of Kir2.1 in vivo by measuring glucose uptake of macrophages in peritoneal exudate cells (PECs) and inflammatory monocytes in peripheral mononuclear cells (PBMCs) after intraperitoneal LPS challenge. Consistently, LPS-induced glucose uptake by these cells was significantly lower in $L y z 2-c r e-K c n j 2^{f / f}$ mice than that in wild-type mice (Figs. 3F and 3G). Together, these data suggest that Kir2.1 promotes glucose uptake and consumption in inflammatory macrophages.

\section{Kir2.1 supports glycolysis offshoots and SGOC metabolism in inflammatory macrophages and its loss-of-function leads to an amino acid starvation phenotype}

A key mechanism for LPS-induced glycolysis is the induction of dimeric PKM2, which enters into a complex with HIF-1 a to drive IL-1 $\beta$ expression (Palsson-McDermott et al., 2015a). As HIF-1a activation was minimally affected by ML133 (Figure S3F), we considered other mechanisms underlying the 
impaired glycolysis by Kir2.1 blockade. While often represented as a linear metabolic flux, glycolysisderived carbons also feed into several offshoots and integrate into different biosynthetic pathways (Chaneton et al., 2012; Keller et al., 2012). The pentose phosphate pathway (PPP) generates pentose sugars for nucleotide synthesis, and another three-step offshoot, the serine synthesis pathway (SSP) diverts glucose-derived carbons into serine, which is further integrated into the serine, glycine, one-carbon (SGOC) metabolic network that includes the folate and methionine cycles (Newman and Maddocks, 2017; Yang and Vousden, 2016) (Fig. 4A). Strikingly, unbiased metabolomics profiling revealed that the key metabolites 3-phosphoserine (3PS, representing the SSP) and ribose 5-phosphate (R5P, representing the PPP), increased in response to LPS but were decreased by ML133 (Fig. 4B). In addition, the enzymes mediating the three-step SSP - Phgdh, Psat1, and Psph - (Fig. 4A), and genes previously described as master regulators of the SSP (Yang and Vousden, 2016), such as Atf4 and Mdm2, were all upregulated by ML133 (Fig. 4C), showing a phenotype similar to a compensatory increase in the SSP upon serine starvation (Maddocks et al., 2013; Ye et al., 2012). Many enzymes involved in SGOC metabolism were also upregulated in ML133-treated inflammatory macrophages (Figure S4A). Moreover, GSEA of RNA-seq data showed that ML133-treated inflammatory macrophages were enriched in 'amino acid transport' and 'SGOC metabolism' (Fig. 4D). Using strategies of pharmacological inhibitor (acute blockade) and genetic depletion (long-term absence) may lead to certain discrepancies in downstream cellular and molecular mechanisms. To reveal the common mechanisms of both ML133 and Kir2.1 deficiency, we analyzed together the RNA-seq data from both ML133-treated and Kir2.1-depleted macrophages upon LPS stimulation. We found 236 overlapped downregulated and 163 overlapped upregulated genes (Fig. 4E). Pathway analysis revealed that the downregulated pathways affected by both ML133 and Kir2.1depletion were mostly related to 'inflammatory response' and 'response to LPS or IL-1' (Fig. 4F). Strikingly, the upregulated pathways were related to 'response to amino acid starvation' and 'regulation of translation' (Fig. 4F). Among these upregulated genes, we found several master sensors and regulators in response to amino acid starvation, including GCN2, PERK, IMPACT, and SLC38A2 (Figure S4B) (Broer and Broer, 2017).

We next used U- $\left[{ }^{13} \mathrm{C}\right]$-glucose tracers to confirm the changes in the SSP and SGOC metabolism when Kir2.1 was blocked during LPS stimulation. ML133 significantly decreased intracellular $m+6$ glucose, $m$ +3 serine, and $m+2$ glycine, suggesting that Kir2.1 supports glucose uptake and the channeling of glucose-derived carbons into the SSP upon LPS stimulation (Figs. 4G and 4H). To assess the contribution of this suppressed SSP to the anti-inflammatory phenotype of ML133, we supplemented cell penetrable 3-PG (Finder and Hardin, 1999; Yang et al., 2014), which is more channeled into the SSP from glycolysis under serine-depleted conditions (Chaneton et al., 2012; Maddocks et al., 2013; Zhang et al., 2012), and found the suppressed IL-1 $\beta$ production by ML133 was partially restored (Figure S4C). Of note, most of the accumulation of intracellular serine and methionine was unlabeled $(m+0)$ (Figures S4D and S4E), indicating their accumulation is largely fueled by exogenous import during inflammation. Strikingly, the LPS-induced accumulation of unlabeled serine, glycine, and methionine (key amino acids fueling SGOC metabolism (Locasale, 2013)) was also greatly blocked by ML133 (Fig. 4I). Similarly, we used U-[13 C]serine tracers and found a decrease of $m+3$ serine, $m+2$ glycine, and $m+0$ methionine due to Kir2.1 
deficiency, recapitulating the impeded serine and methionine uptake (Figure S4F). These results together highlight a role of Kir2.1 in the nutrient supply fueling glycolysis offshoots and SGOC metabolism during LPS-induced inflammation.

\section{Kir2.1 supports S-adenosylmethionine generation and configures histone methylation in inflammatory macrophages}

Through coupling with the methionine cycle, the SGOC metabolic network acts as an integrator of nutrient status to generate diverse outputs, including the primary methyl donor S-adenosylmethionine (SAM) (Locasale, 2013; Yang and Vousden, 2016; Yu et al., 2019). We and others have previously showed that glucose can provide carbons to feed SAM generation through de novo ATP synthesis (Maddocks et al., 2016; Newman and Maddocks, 2017; Yu et al., 2019) (Fig. 5A). Using U-[ $\left.{ }^{13} \mathrm{C}\right]$-glucose, we found ML133 led to a decrease in LPS-induced $m+5$ to 9 SAM (via both the PPP and SSP) and its demethylation product S-adenosylhomocysteine (SAH) (Figs. 5A and 5B), as well as $m+5$ to 9 ATP (Figure S5A). The total amount of SAM was also reduced by ML133 (Figure S5B). Using U- $\left[{ }^{13} \mathrm{C}\right]$-serine tracers, we obtained similar results that ML133 or Kir2.1 deficiency decreased the LPS-induced incorporation of $\mathrm{U}-\left[{ }^{13} \mathrm{C}\right]$-serine-derived carbons into $\mathrm{m}+1$ to $4 \mathrm{SAM}$, as well as the total amount of SAM (Figs. 5C, 5D, and S5C). Given that Kir2.1 blockade led to impaired nutrient uptake, exogenous glucose or amino acids (serine, glycine, or methionine) that donate carbons into SGOC metabolism only had mild rescue effects on the suppressed IL-1 $\beta$ production by ML133 (Figures S5D-S5F). However, addition of SAM dose-dependently restored this suppressed IL-1 $\beta$ production (Figs. $5 \mathrm{E}$ and $5 \mathrm{~F}$ ), suggesting a role of Kir2.1 in supporting LPS-induced SAM generation by providing the supply of extracellular nutrients.

SAM is the universal methyl donor for all methylation reactions in cells, which plays critical roles in the chromatin state and gene transcription (Goll and Bestor, 2005). SAM availability can directly modulate several epigenetic methylation marks required for the maintenance of downstream gene transcription (Mentch et al., 2015; Mews et al., 2014; Shiraki et al., 2014; Shyh-Chang et al., 2013). RNA-seq analysis of the expression of 183 annotated SAM-dependent methyltransferase enzymes (Kottakis et al., 2016) revealed that Kir2.1 deficiency upregulated all methyltransferases for histone $\mathrm{H} 3$ methylation at lysine 36 (H3K36me) (Wagner and Carpenter, 2012) compared to those for other histone methylation marks (Figs. 5G, 5H, and S5G). Among the most upregulated methyltransferase genes, ASH1L and NSD1 have specific mono- and dimethylase activity for H3K36, and SETD2 is the only reported trimethylase catalyzing the trimethylation of H3K36 (Fig. 5G) (Chen et al., 2017; Wagner and Carpenter, 2012). H3K36me3 is one of the most dynamic histone methylation marks and its main distribution appears in a wide range of gene body regions as a SAM 'sink' (Ye et al., 2017), making it more sensitive to SAM availability for downstream gene expression (Wagner and Carpenter, 2012). To test whether Kir2.1induced SAM generation fuels histone methylation such as H3K36me3 upon LPS stimulation, we coupled chromatin immunoprecipitation with quantitative PCR (ChIP-qPCR) and found that LPS-induced 
occupancy of H3K36me3 in $/ / 1 b$ gene-body regions farther from the 5 ' end (Adamik et al., 2013) was significantly decreased by ML133 or Kir2.1 deficiency (Figs. $5 \mathrm{I}$ and S5H). In addition, LPS-induced H3K36me3 enrichment in the gene-body regions of other inflammatory factors including $/ 11 \mathrm{a}, \| 118$, and Cxcl10 were also decreased (Figs. 5J and S5H). In contrast, H3K36me3 enrichment in the gene-body regions of Tnf was unaffected in these experiments (Figure S5I). We thus conclude that deregulation of histone methylation marks, at least H3K36me3, contributes to the anti-inflammatory outcome of Kir2.1 loss-of-function.

\section{Kir2.1-mediated regulation of membrane potential orchestrates metabolic-epigenetic reprogramming in inflammatory macrophages}

Given that monovalent cations such as $\mathrm{K}^{+}$regulate the membrane potential, which indirectly controls the flux of $\mathrm{Ca}^{2+}$ and intracellular signaling pathways (Feske et al., 2015; Franchini et al., 2004; Lam and Schlichter, 2015), we initially investigated whether Kir2.1 stimulates inflammatory macrophages by modulating $\mathrm{Ca}^{2+}$ homeostasis. In LPS-stimulated BMDMs loaded with $\mathrm{Ca}^{2+}$-sensitive fluorescent dye Fluo-4-AM, we found an elevation of cytosolic $\mathrm{Ca}^{2+}$ level in response to ML133 (Figure S6A). However, when we used BAPTA or EGTA to chelate the extracellular $\mathrm{Ca}^{2+}$ or BAPTA-AM to chelate the intracellular $\mathrm{Ca}^{2+}$, the inhibitory effect of ML133 on LPS-induced IL-1 $\beta$ production was not affected (Figures S6BS6F). Notably, BAPTA-AM showed an additional inhibitory effect on the production of IL-1 $\beta$ (Figures S6E and $6 \mathrm{~F}$ ), suggesting a separate contribution of intracellular $\mathrm{Ca}^{2+}$ in parallel to ML133. Consistent with idea, when we depleted ER $\mathrm{Ca}^{2+}$ store by thapsigargin (TG), although TG alone was able to reduce the production of IL-1 $\beta$, ML133 still had a similar inhibitory efficiency on IL-1 $\beta$ production (Figure S6G). Moreover, the effect of ML133 was independent of the concentrations of extracellular $\mathrm{Ca}^{2+}(0,1.2,2.4$, and $3.6 \mathrm{mM}$ ) or the other divalent cations $\mathrm{Mg}^{2+}$ and $\mathrm{Mn}^{2+}$ (Figures $\mathrm{S} 6 \mathrm{H}$ and S6I). We thus conclude that the changes in $\mathrm{Ca}^{2+}$ homeostasis is not required for the anti-inflammatory outcome of Kir2.1 blockade.

Given the critical role of Kir2.1 in maintaining $V_{m}$ of inflammatory macrophages (Figs. 1E and 1F), we considered the possibility that Kir2.1 promotes LPS-induced inflammation by its regulation of $V_{m}$. We first examine whether $V_{m}$ depolarization by other means results in an analogous suppression of inflammatory macrophages. Increased extracellular $\mathrm{K}^{+}\left(\left[\mathrm{K}^{+}\right]_{\mathrm{e}}\right)$ is widely used to depolarize $\mathrm{V}_{\mathrm{m}}$. We found the $\mathrm{V}_{\mathrm{m}}$ of both resting and LPS-stimulated macrophages was depolarized by elevated $\left[\mathrm{K}^{+}\right]_{\mathrm{e}}$, as determined by either patch clamp experiments or a membrane sensitive fluorochrome DiBAC4(3) (Eil et al., 2016) (Figures S6J and S6K). Strikingly, elevation of $\left[\mathrm{K}^{+}\right]_{\mathrm{e}}$ similarly decreased the LPS-induced IL-1 $\beta$ without affecting the TNF-a (Fig. 6A), as well as glucose uptake detected by intracellular $m+6$ glucose using $U-\left[{ }^{13} \mathrm{C}\right]$-glucose tracers (Fig. 6B). The effect of elevated $\left[\mathrm{K}^{+}\right]_{\mathrm{e}}$ was not due to an osmotic effect, as choline chloride or mannitol did not induce a similar suppression of IL-1 $\beta$ production (Figure $\mathrm{S} 6 \mathrm{~L}$ ). Gramicidin is another widely used strategy to depolarize $\mathrm{V}_{\mathrm{m}}$ by forming pores permeable to both $\mathrm{K}^{+}$and $\mathrm{Na}^{+}$in the plasma membrane (Munoz-Planillo et al., 2013). As expected, gramicidin depolarized the $V_{m}$ of inflammatory 
macrophages (Figure S6K), and it recapitulated the suppressed LPS-induced IL-1 $\beta$ production and glucose uptake, but not the TNF-a (Figs. $6 \mathrm{C}$ and $6 \mathrm{D}$ ). Furthermore, using $\mathrm{U}-\left[{ }^{13} \mathrm{C}\right]$-glucose, we found that elevated $\left[\mathrm{K}^{+}\right]_{e}$ and gramicidin led to a decrease in LPS-induced $m+3$ serine, $m+5$ to 9 ATP, and $m+5$ to 9 SAM, as well as unlabeled $\mathrm{m}+0$ serine and methionine (Figs. $6 \mathrm{E}$ and $6 \mathrm{~F}$ ). Elevated $\left[\mathrm{K}^{+}\right]_{\mathrm{e}}$ also reduced the enrichment of $\mathrm{H} 3 \mathrm{~K} 36 \mathrm{me} 3$ in the gene-body regions of $/ / 1 \mathrm{~b}, / / 1 \mathrm{a}, / / 18$, and $\mathrm{CxC} / 10$ loci (Figs. $6 \mathrm{G}$ and $6 \mathrm{H}$ ). Together, these data suggest that the maintenance of membrane potential may be a common mechanism that orchestrates metabolic-epigenetic reprogramming in inflammatory macrophages.

\section{Kir2.1 supports nutrient supply by promoting the surface expression of nutrient transporters during LPS-induced inflammation}

Nutrient import is the proximal step at which intracellular metabolism can be tightly regulated. Cells require adaptations in nutrient transport mechanisms to meet different metabolic demands (McCracken and Edinger, 2013). Consistent with this idea, glucose transporter expression levels are elevated in proliferating cells and in a wide variety of tumor types (Adekola et al., 2012). To investigate the mechanisms underlying the regulation of nutrient import by Kir2.1 in inflammatory macrophages, we first analyzed the RNA-seq data with the KEGG (Kyoto Encyclopedia of Genes and Genomes) and Reactome pathway databases. Strikingly, apart from pathways related to inflammation, Kir2.1 blockade led to a strong enrichment for the pathways related to endocytosis, vesicle transport, and membrane trafficking (Figs. 7A and 7B). Given the critical roles of surface transporters in the regulation of nutrient import, we next evaluated the potential contribution of Kir2.1 to the surface expression of nutrient transporters fueling glucose and amino acid metabolism. Glucose transporter 1 (GLUT1) is the primary transporter that rewires glucose metabolism in LPS-stimulated macrophages (Freemerman et al., 2014). While the mRNA expression was not affected (Figure S7A), ML133 dose-dependently decreased the membrane GLUT1 expression in LPS-stimulated macrophages examined by flow cytometry (Fig. 7C). This effect was also confirmed by immunoblotting for biotinylated cell-surface proteins in ML133-treated or Kir2.1depleted inflammatory macrophages (Figs. 7C and S7B). Consistently, this decreased membrane GLUT1 expression was recapitulated by elevated $\left[\mathrm{K}^{+}\right]_{e}$ (Fig. 7D). Among the membrane amino acid transporters, L-type amino acid transporter (LAT1) together with 4F2 cell-surface antigen heavy chain (4F2hc, also known as CD98) transport large neutral amino acids including methionine (McCracken and Edinger, 2013; Yanagida et al., 2001). Both ML133 and elevated $\left[\mathrm{K}^{+}\right]_{\mathrm{e}}$ decreased the surface expression of CD98 in LPSstimulated macrophages (Fig. 7E), and depolarization by gramicidin gave similar results including GLUT1 and CD98 (Figs. 7F and 7G). These results further indicated the contribution of membrane potential to the nutrient import in inflammatory macrophages.

The surface expression and activity of glucose transporters were regulated by lipid rafts-mediated trafficking and internalization (Kumar et al., 2004; Michel and Bakovic, 2007; Yan et al., 2018). Nearly 80\% of GLUT 4 is internalized by a lipid rafts-dependent mechanism which can be blocked by the cholesterolchelating drug nystatin (Blot and McGraw, 2006; Ros-Baro et al., 2001). Without affecting TLR4-mediated 
downstream signaling upon LPS stimulation (Figure S7C), nystatin partially restored the decreased level of surface GLUT1, the suppressed glucose uptake, and IL-1 $\beta$ production but not TNF- $a$ when Kir2.1 was blocked by ML133 or depleted (Figs. 7H-7K and S7D). Nystatin also rescued the enrichment of H3K36me3 in the gene-body regions of $/ / 1 a, / / 1 b, / / 18$, and $C x c / 10$ loci in Kir2.1-depleted inflammatory macrophages (Figure S7E). Last, nutrient transporters including GLUT1, CD98, and LAT1 are ARF6/GRP1 cargo proteins that can be recycled back to the plasma membrane via the tubular recycling endosome (Eyster et al., 2009; Finicle et al., 2018; Maldonado-Baez et al., 2013; McCracken and Edinger, 2013). Strikingly, a constitutively active mutant of GRP1 (S155D/T280D, GRP1 DD mutant), which forces the recycling of these transporters back to the plasma membrane and prevents their loss (Finicle et al., 2018; Li et al., 2012), largely restored the ML133-induced suppression of IL-1 $\beta$ (Fig. 7K), further strengthening the contribution of surface nutrient transporters loss to the anti-inflammatory outcome of Kir2.1 blockade.

\section{Discussion}

The coordination between metabolism and epigenetics has been proposed as a key mechanism in immunity (Chisolm and Weinmann, 2018; Phan et al., 2017), but how they are supported by nutrient availability remains poorly understood. In contrast to tumor cells or activated T cells, LPS stimulation dose not induce rapid proliferation of macrophages. However, it also creates increasing metabolic demands that would be supported by extracellular nutrients. The present work provides evidence for fundamental membrane potential control of optimizing nutrient acquisition and utilization for intracellular metabolic and epigenetic reprogramming in inflammatory macrophages (Figure S7F). We propose a model whereby Kir2.1-mediated adaptation in nutrient import (including glucose and amino acids) fueling SAM generation and epigenetically driving LPS-induced inflammation. Mechanistically, we reveal an unexpected role of Kir2.1 in the adaptive regulation of surface nutrient transporters levels in LPS-stimulated macrophages.

Recently, an ionic checkpoint of the elevated $\left[\mathrm{K}^{+}\right]_{\mathrm{e}}$ that blocks $\mathrm{T}$ cell function has been found within the tumor microenvironment, and this elevated $\left[\mathrm{K}^{+}\right]_{\mathrm{e}}$ impairs $\mathrm{T}$ cell effector functions but promotes $\mathrm{T}$ cell stemness (Eil et al., 2016; Vodnala et al., 2019). Augmenting $\mathrm{K}^{+}$efflux in tumor-specific T cells improves effector functions and enhances tumor clearance and survival (Eil et al., 2016), while exposure to increased $\left[\mathrm{K}^{+}\right]_{e}$ enhances the persistence and anti-tumor function of T cells (Vodnala et al., 2019). Changes in environmental $\mathrm{K}^{+}$concentrations have also been reported in different inflammation-related pathophysiological situations (Billman, 1994; Gido et al., 1997; Levite et al., 2000). Disturbances in the concentrations of different ions are closely associated with critical inflammatory disorders, including sepsis and severe burns (Lee, 2010). Accordingly, modulating the ionic regulation of immune cells may represent a potential therapeutic approach for treating inflammatory diseases. Consistent with this idea, Kir2.1 loss-of-function impaired LPS- and infection-induced inflammatory gene expression and rendered mice resistant to sepsis. Moreover, ML133 suppressed IL-1 $\beta$ production in freshly-isolated synovial fluid cells from gouty patients, suggesting Kir2.1 as a potential target for treating inflammatory diseases. 
However, given the expression of Kir2.1 also in other cell types such as endothelial cells, much work remains to determine the systemic effect of targeting Kir2.1 during inflammatory diseases.

Besides the suppressed LPS-induced inflammation, another key phenotype induced by both ML133 and Kir2.1 depletion is nutrient starvation. Several master regulators in response to amino acid starvation such as GCN2, PERK, IMPACT, and SLC38A2 (Broer and Broer, 2017) were also upregulated. There is growing evidence that local nutrient limitations at immune effector sites can be obstacles to both antimicrobial and anti-tumor immunity (Olenchock et al., 2017). Understanding how the interactions among microenvironment factors, immune cell nutrient demands, and cellular metabolic state shape the "metabolic phenotyping" is critical to obtain a more complete understanding of immune cell metabolism. Moreover, instead of acting alone, different types of nutrients would synergistically feed the generation of specific immunometabolites to modulate immune functions. Although other metabolic pathways may also be regulated by Kir2.1 as the low specificity and selectivity of amino acid transporters, our study unveils an ionic control on the synergism of glucose and SGOC metabolism to epigenetically drive LPSinduced inflammation by promoting SAM generation. As a universal methyl donor, the dynamic production and utilization of SAM is critical for the regulation of gene expression by methylation reactions. As a SAM 'sink', H3K36me is one of the more dynamic histone methylation marks required for transcription elongation and splicing (Wagner and Carpenter, 2012; Ye et al., 2017). We found a different sensitivity to the SAM supply and H3K36me regulation between IL-1 13 (also a set of inflammatory genes) and TNF-a, which may provide an explanation for the distinct sensitivity to the metabolic control of these two important inflammatory cytokines during inflammation.

Our study additionally highlights a Kir2.1 control on the adaptations in nutrient uptake of inflammatory macrophages by dynamically regulating the surface expression of nutrient transporters, including GLUT1 (glucose) and CD98 (amino acids). Given the apical position of the nutrient transporters in metabolic pathways, these proteins are intriguing pharmacologic targets for cancer treatment. The strategy of starving cancer cells of required amino acids including serine and methionine has been proved to be effective both in mice and humans (Gao et al., 2019; Locasale, 2013; Maddocks et al., 2013). More recently, efforts have been directed at blocking nutrient import rather than availability. Several compounds that inhibit nutrient transport in tumor cells can prevent proliferation and induce cell death (McCracken and Edinger, 2013). Given that $V_{m}$ regulation on the surface retention of nutrient transporters may be a common mechanism during inflammation and cancer, it will be important to further investigate the roles of other ionic channels on nutrient uptake, as well as the nutrients acquired through those less well characterized transporters.

In sum, this current study unveils a Kir2.1 control acting on macrophage activation and shows that targeting ion channels may have implications for treating inflammatory diseases.

\section{Experimental Model And Subject Details}

\section{Mice}


C57BL/6 mice were purchased from the Model Animal Research Center of Nanjing University, Lyz2-cre mice were purchased from the Jackson Laboratory, and the $K c n j 2^{f / f}$ mice were kind gifts from by Professor Mark T. Nelson of the University of Vermont. Kcnj2 $2^{f / f}$ mice were crossed with Lyz2-cre mice to obtain Lyz2-cre-Kcnj2 $2^{f / f}$ mice. Animals were housed in a specific pathogen-free facility in the University Laboratory Animal Center. The animal experimental protocols were approved by the Review Committee of Zhejiang University School of Medicine and were in compliance with institutional guidelines.

\section{Cells}

HEK293T cells were from ATCC and cultured in Dulbecco's modified Eagle's medium (DMEM).

To obtain Mouse peritoneal macrophages, in day 0, mice were injected peritoneally with $2.5 \mathrm{ml}$ of $4 \%$ thioglycolate (Merck) medium, and in day 3 to 5 , peritoneal macrophages were obtained by flush the peritoneal cavity with PBS or DMEM medium. Each mouse usually yields approx. $2 \times 10^{7}$ cells, and the non-adherent cells were discarded after macrophages adhere.

Bone marrow cells were flushed from tibias and femurs with cold DMEM and cultured in DMEM supplemented with $10 \%$ fetal bovine serum (FBS), $1 \%$ penicillin/streptomycin, and $10 \mathrm{ng} / \mathrm{ml}$ macrophage colony-stimulating factor (PeproTech) to generate BMDMs.

The iBMDMs were a kind gift from Prof. Shao (National Institute of Biological Sciences, China). J774.1 (from ATCC) and iBMDMs were cultured in DMEM supplemented with $10 \%$ FBS and $1 \%$ penicillin/streptomycin.

Synovial fluid cells $\left(5 \times 10^{5}\right.$ /well) were seeded in 12-well plates in RPMI 1640 supplemented with $10 \%$ FBS. They were stimulated with $100 \mathrm{ng} / \mathrm{ml}$ LPS and inhibitors as indicated for $12 \mathrm{~h}$. Then sample supernatants were used for IL-1 $\beta$ measurements using ELISA.

\section{Human Subjects}

Synovial fluid (approximate 4-5 ml) was obtained from two gouty patients (a 36-year-old man and a 56year-old man) with serum uric acid levels $>500 \mathrm{mmol} / \mathrm{l}$ and knee effusion. The patients were not involved in previous procedures or drug tests. To use these clinical materials for research purposes, prior patient written informed consent and approval from the Institutional Research Ethics Committee of The Second Affiliated Hospital of Zhejiang University School of Medicine were obtained (approval no. 2018-064). Synovial fluid cell $\left(5 \times 10^{5}\right)$ were seeded in 12-well plates in RPMI 1640 supplemented with $10 \%$ FBS. They were stimulated with $100 \mathrm{ng} / \mathrm{ml}$ LPS and inhibitors as indicated for $12 \mathrm{~h}$. Then sample supernatants were used for IL-1 $\beta$ detection using ELISA.

\section{Reagents}

LPS from Escherichia coli 0111:B4, U-[ $\left.{ }^{13} \mathrm{C}\right]$-serine, serine, glycine, methionine, SAM, 3-PG and $\mathrm{BaCl}_{2}$ were from Sigma; ML133 was from Selleck; amino-acid- and KCl- deficient DMEM was from Shanghai 
BasalMedia Technologies; dialyzed FBS was from Biological Industries; and U-[13 C]-glucose was from Cambridge Isotope Laboratories; 2NBDG was from Cayman; Nystatin was from Sigma.

The following Biolegend antibodies were used: pro-IL-1 $\beta$ (AF-401-NA,) was from R\&D systems; anti-Kir2.1 (19965-1-AP) was from Proteintech; anti-phospho-p65 (\#3033), anti-p65 (\#8242), anti-phospho-IkBa (\#2859), anti-IKBa (\#4814), anti-phospho-Erk (\#4370), anti-Erk (\#4695), anti-phospho-JNK (\#9255), antiJNK (\#9252), anti-phospho-P38 (\#4511), anti-P38 (\#8690), anti-phospho-AKT (\#4060), anti-AKT (\#2920), anti-H3K36me3 (\#4909) were from Cell Signaling Technology; anti-GLUT1 (ab115730) was from Abcam, PE anti-mouse CD98 (\#128207) was from Bioledgend, anti- $\beta$-actin (M1210-2), anti-rabbit IgG-HRP (HA1001), anti-mouse IgG-HRP (HA1006), and anti-goat IgG-HRP (HA1005) were from HuaBio, DyLight549 goat anti-rabbit lgG [H + L] (70-GAR5492) was from MultiSciences, and the ChIP kit (\#9005) was from Cell Signaling Technology.

\section{Method Details}

\section{Immunoblot Analysis}

Cells were lysed in $2 \times$ SDS buffer $(100 \mathrm{mM}$ Tris-HCl, 4\% SDS, 20\% glycerol, 2\% 2-mercaptoethanol, and $0.05 \%$ bromophenol blue) followed by boiling for $10 \mathrm{~min}$. Then samples were separated by SDS-PAGE on $12 \%$ gels, after which the proteins were transferred to nitrocellulose membranes (\#28637358, Pall). The membranes were blocked for $1 \mathrm{~h}$ in blocking buffer (5\% skimmed milk and $0.1 \%$ Tween 20 in TBS), and then incubated with primary antibodies in 5\% BSA overnight. The membranes were incubated with secondary antibodies in $0.1 \%$ Tween 20 in TBS at room temperature for $1 \mathrm{~h}$. To detect proteins, we used ECL blotting reagents (Thermo Fisher).

\section{In vivo LPS challenge}

Mice were injected intraperitoneally with LPS ( $25 \mathrm{mg} / \mathrm{kg}$ body weight) alone or along with ML133 (30 mg/kg body weight). In the sepsis model, mice were sacrificed $4 \mathrm{~h}$ after LPS challenge, and the serum levels of IL-1 $\beta$ and TNF-a were measured by ELISA (Thermo Fisher) according to the manufacturer's instructions. For mouse survival rate analysis, mice were injected intraperitoneally with LPS $(20 \mathrm{mg} / \mathrm{kg}$ body weight) alone or along with ML133 (30 mg/kg body weight), then survival rates were analyzed.

\section{Bacterial infection}

For in vitro bacterial infection assay, mouse peritoneal macrophages were seeded in 12 well plate $(5 \times$ $10^{5}$ /well) and infected with $5 \times 10^{6}$ E.coli or salmonella SL1344 for $6 \mathrm{~h}$ in the presence or absence of ML133 $(25 \mu \mathrm{M})$ followed by qPCR analysis of inflammatory genes transcription. For in vivo bacterial infection assay, 8-week-old mice were injected with $1 \times 10^{7}$ bacteria peritoneally in the presence or absence of ML133 (30 mg/kg), 6 hours later, the mice were sacrificed and the serum levels of IL-1 $\beta$ and TNF-a were measured by ELISA (Thermo Fisher) according to the manufacturer's instructions. 


\section{Quantitative PCR (qPCR)}

RNA was extracted using RNAiso Plus reagent (Takara). Complementary DNA was synthesized using HiScript ${ }^{\circledR}$ II Reverse Transcriptase (Vazyme Biotech) according to the manufacturer's protocol. qPCR was performed using SYBR Green (Vazyme Biotech) on a CFX96 Touch Real Time PCR (BioRad). The PCR program was initial denaturation at $95^{\circ} \mathrm{C}$ for $2 \mathrm{~min}$, then cDNA amplification for 40 cycles at $95^{\circ} \mathrm{C}$ for $30 \mathrm{~s}$ and $60^{\circ} \mathrm{C}$ for $30 \mathrm{~s}$. The samples were individually normalized to Gapdh.

The primers are listed in the table.

\begin{tabular}{|lll|}
\hline Gene & Forward 5'to 3' & Reverse 5'to $\mathbf{3}^{\prime}$ \\
\hline Gapdh & AGGTCGGTGTGAACGGATTTG & TGTAGACCATGTAGTTGAGGTCA \\
\hline I/1b & ATCAACCAACAAGTGATATTCTCCAT & GGGTGTGCCGTCTTTCATTAC \\
\hline Tnf & CCTGTAGCCCACGTCGTAG & GGGAGTAGACAAGGTACAACCC \\
\hline Ila & GGAGAAGACCAGCCCGTGTTGCT & CCGTGCCAGGTGCACCCGACTT \\
\hline
\end{tabular}

The Seahorse XF96 analyzer (Agilent Technologies) was used to measure extracellular ECAR. BMDMs were seeded on XF96 plates at $8 \times 10^{4}$ cells/well one day prior to the XF assay. On the day of assay, the medium was replaced with assay medium composed of XF Base Medium without phenol red (Agilent Technologies, 103335-100) supplemented with $10 \mathrm{mM}$ glucose, $2 \mathrm{mM} \mathrm{L-glutamine,} 1 \mathrm{mM}$ sodium pyruvate, adjusted to $\mathrm{pH} 7.4$ and incubated at $37^{\circ} \mathrm{C}$ without $\mathrm{CO}_{2} 45 \mathrm{~min}$ prior to XF assay. The assay protocol was as follows: baseline measurement with 5 cycles ( $\operatorname{mix} 3 \mathrm{~min}$, wait $0 \mathrm{~min}$, measure $3 \mathrm{~min}$ ); then LPS and/or ML133 was injected with the final concentration of $500 \mathrm{ng} / \mathrm{ml}$ or $25 \mu \mathrm{M}$ respectively and measurements continued with 10-99 cycles ( $\mathrm{mix} 3 \mathrm{~min}$, wait $0 \mathrm{~min}$, measure $3 \mathrm{~min}$ ). Data shown are the mean $\pm S D, n=6$ technical replicates.

\section{$\left[{ }^{3} \mathrm{C}\right]$-glucose and $\left[{ }^{13} \mathrm{C}\right]$-serine tracing}

Mouse peritoneal macrophages $\left(5 \times 10^{6} /\right.$ dish) were seeded in $60-\mathrm{mm}$ dishes in complete DMEM medium (supplemented with $10 \%$ fetal bovine serum (FBS), $1 \%$ penicillin/streptomycin) to adhere. In metabolite tracing experiments, complete DMEM medium was replaced with glucose- or serine-deficient DMEM supplemented with $25 \mathrm{mM} \mathrm{U}-\left[{ }^{13} \mathrm{C}\right]$-glucose (Cambridge Isotope Laboratories) or $0.4 \mathrm{mM} \mathrm{U}-\left[{ }^{13} \mathrm{C}\right]$-serine (Sigma) (supplemented with 10\% dialyzed fetal bovine serum (FBS), 1\% penicillin/streptomycin). Cells were treated with $500 \mathrm{ng} / \mathrm{ml}$ LPS in the presence or absence of compounds as indicated for 6 hours. For metabolite extraction, cells were washed twice with PBS and once more with $0.9 \% \mathrm{NaCl}$. After completely aspirating the liquid, the plates were put on dry ice, $1 \mathrm{ml}$ of $80 \%(\mathrm{v} / \mathrm{v})$ methanol (pre-chilled to $-80{ }^{\circ} \mathrm{C}$ ) was added, and the plates were kept at $-80^{\circ} \mathrm{C}$ for $2 \mathrm{~h}$. The plates were scraped on dry ice, the cell lysate/methanol mixture was transferred to a 2 -ml tube on dry ice, then another $0.8 \mathrm{ml}$ of $80 \%$ methanol 
was added to wash the plate and transfer the mixture to a tube. Each tube was centrifuged at $14,000 \mathrm{~g}$ for 20 min at $4{ }^{\circ} \mathrm{C}$ and the metabolite-containing supernatant was transferred to a new tube and lyophilized. Metabolites were analyzed using a TSQ Quantiva Ultra triple-quadrupole mass spectrometer coupled with an Ultimate 3000 UPLC system (Thermo Fisher, CA) equipped with a heated electrospray ionization probe. Chromatographic separation was done by gradient elution on a reversed-phase UPLC HSS T3 column $(2.1 \times 100 \mathrm{~mm}, 1.7 \mu \mathrm{m}$, Waters). Mobile phase A consisted of $2 \mathrm{mM}$ perfluoroheptanoic acid in $100 \% \mathrm{H}_{2} \mathrm{O}$, and mobile phase $B$ of $100 \%$ acetonitrile. A 10-min gradient with a flow rate of 300 $\mu \mathrm{L} / \mathrm{min}$ was used as follows: 0-1.5 min at $2 \% \mathrm{~B} ; 1.5-5 \mathrm{~min}, 2-98 \% \mathrm{~B} ; 5-7 \mathrm{~min}, 98 \% \mathrm{~B} ; 7-7.1 \mathrm{~min}, 2 \% \mathrm{~B}$; 7.1-10 min $2 \% \mathrm{~B}$. The column chamber was held at $45^{\circ} \mathrm{C}$ and the sample tray at $10{ }^{\circ} \mathrm{C}$. Data were acquired in Selected Reaction Monitoring in positive/negative switch ion mode and optimal transitions are reported in the table as indicated below. Both the precursor and fragment ions were separately collected at a resolution of $0.7 \mathrm{FWHM}$. The source parameters were as follows: spray voltage, $3000 \mathrm{~V}$; ion transfer tube temperature, $350^{\circ} \mathrm{C}$; vaporizer temperature, $300^{\circ} \mathrm{C}$; sheath gas flow rate, $35 \mathrm{Arb}$; auxiliary gas flow rate, $12 \mathrm{Arb}$. CID gas, $1.5 \mathrm{mTorr}$. Data analysis and quantitation were performed using Xcalibur 3.0.63 (Thermo Fisher, Carlsbad, CA). The liquid chromatography-mass spectrometry was done at the Metabolomics Facility of Technology Center for Protein Sciences, Tsinghua University, Beijing.

\section{Metabolite quantification and metabolomics}

Mouse peritoneal macrophages $\left(5 \times 10^{6} /\right.$ dish) were seeded in $60-\mathrm{mm}$ dishes in complete DMEM medium (supplemented with $10 \%$ fetal bovine serum (FBS), $1 \%$ penicillin/streptomycin) to adhere. Cells were treated with $500 \mathrm{ng} / \mathrm{ml}$ LPS in the presence or absence of compounds as indicated for 6 hours. Then metabolites were extracted as above. For unbiased and targeted metabolomics, samples were analyzed at Applied Protein Technology (Shanghai, China).

For unbiased metabolomics, LC-MS/MS Analysis (HILIC/MS) were performed using an UHPLC (1290 Infinity LC, Agilent Technologies) coupled to a quadrupole time-of-flight (AB Sciex TripleTOF 6600). For HILIC separation, samples were analyzed using a $2.1 \mathrm{~mm} \times 100 \mathrm{~mm}$ ACQUIY UPLC BEH $1.7 \mu \mathrm{m}$ column (waters, Ireland). In both ESI positive and negative modes, the mobile phase contained A = $25 \mathrm{mM}$ ammonium acetate and $25 \mathrm{mM}$ ammonium hydroxide in water and $\mathrm{B}=$ acetonitrile. The gradient was $85 \%$ B for $1 \mathrm{~min}$ and was linearly reduced to $65 \%$ in $11 \mathrm{~min}$, and then was reduced to $40 \%$ in $0.1 \mathrm{~min}$ and kept for $4 \mathrm{~min}$, and then increased to $85 \%$ in $0.1 \mathrm{~min}$, with a $5 \mathrm{~min}$ re-equilibration period employed. The ESI source conditions were set as follows: Ion Source Gas1 (Gas1) as 60, Ion Source Gas2 (Gas2) as 60, curtain gas (CUR) as 30 , source temperature: $600^{\circ} \mathrm{C}$, lonSpray Voltage Floating (ISVF) $\pm 5500 \mathrm{~V}$. In MS only acquisition, the instrument was set to acquire over the $\mathrm{m} / \mathrm{z}$ range 60-1000 Da, and the accumulation time for TOF MS scan was set at $0.20 \mathrm{~s} / \mathrm{spectra}$. In auto MS/MS acquisition, the instrument was set to acquire over the $\mathrm{m} / \mathrm{z}$ range $25-1000 \mathrm{Da}$, and the accumulation time for product ion scan was set at $0.05 \mathrm{~s} / \mathrm{spectra}$. The product ion scan is acquired using information dependent acquisition (IDA) with high sensitivity mode selected. The collision energy (CE) was fixed at $35 \mathrm{~V}$ with $\pm 15 \mathrm{eV}$. Declustering potential (DP) was set as $\pm 60 \mathrm{~V}$ 
A targeted metabolic analysis was performed using an LC-MS/MS system. The dried metabolites were dissolved in $100 \mu \mathrm{L}$ of acetonitrile/ $\mathrm{H}_{2} \mathrm{O}(1: 1, \mathrm{v} / \mathrm{v})$ and centrifuged (13000 rpm) for $15 \mathrm{~min}$. Electrospray ionization was conducted with an Agilent 1290 Infinity chromatography system and AB Sciex QTRAP 5500 mass spectrometer. $\mathrm{NH}_{4} \mathrm{COOH}(15 \mathrm{mM})$ and acetonitrile were used as mobile phases $\mathrm{A}$ and $\mathrm{B}$, respectively. A binary solvent gradient was used as follows: $\mathrm{A}, \mathrm{NH}_{4} \mathrm{COOH} ; \mathrm{B}, 0-18$ min at $90-40 \%$ acetonitrile; 18-18.1 min at 40-90\% acetonitrile; and 18.1-23 $\mathrm{min}$ at $90 \%$ acetonitrile. The LCMS/MS was operated in the negative mode under the following conditions: source temperature, $450{ }^{\circ} \mathrm{C}$; ion source gas 1, 45; ion source gas 2, 45; curtain gas, 30 ; and ion spray voltage floating (ISVF), $-4500 \mathrm{~V}$.

\section{RNA-sequencing and differential expressed genes analysis}

Library preparation for Transcriptome sequencing. A total amount of $3 \mu \mathrm{g}$ RNA per sample was used as input material for the RNA sample preparations. Sequencing libraries were generated using NEBNext ${ }^{\circledR}$ UltraTM RNA Library Prep Kit for Illumina ${ }^{\circledR}$ (NEB, USA) following manufacturer's recommendations and index codes were added to attribute sequences to each sample. Briefly, mRNA was purified from total RNA using poly-T oligo-attached magnetic beads. Fragmentation was carried out using divalent cations under elevated temperature in NEB. Next First Strand Synthesis Reaction Buffer (5x). First strand cDNA was synthesized using random hexamer primer and M-MuLV Reverse Transcriptase (RNase $\left.\mathrm{H}^{-}\right)$. Second strand cDNA synthesis was subsequently performed using DNA Polymerase I and RNase H. Remaining overhangs were converted into blunt ends via exonuclease/polymerase activities. After adenylation of 3' ends of DNA fragments, NEBNext Adaptor with hairpin loop structure were ligated to prepare for hybridization. In order to select cDNA fragments of preferentially $250 \sim 300$ bp in length, the library fragments were purified with AMPure XP system (Beckman Coulter, Beverly, USA). Then $3 \mu$ I USER Enzyme (NEB, USA) was used with size-selected, adaptor-ligated cDNA at $37^{\circ} \mathrm{C}$ for 15 min followed by 5 min at $95^{\circ} \mathrm{C}$ before PCR. Then PCR was performed with Phusion High-Fidelity DNA polymerase, Universal PCR primers and Index (X) Primer. At last, PCR products were purified (AMPure XP system) and library quality was assessed on the Agilent Bioanalyzer 2100 system

Clustering and sequencing. The clustering of the index-coded samples was performed on a cBot Cluster Generation System using TruSeq PE Cluster Kit v3-cBot-HS (Illumia) according to the manufacturer's instructions. After cluster generation, the library preparations were sequenced on an Illumina Hiseq platform and $125 \mathrm{bp} / 150 \mathrm{bp}$ paired-end reads were generated.

Quantification of gene expression level. featureCounts v1.5.0-p3 was used to count the reads numbers mapped to each gene. And then FPKM of each gene was calculated based on the length of the gene and reads count mapped to this gene. FPKM, expected number of Fragments Per Kilobase of transcript sequence per Millions base pairs sequenced, considers the effect of sequencing depth and gene length for the reads count at the same time, and is currently the most commonly used method for estimating gene expression levels.

Differential expression analysis. Differential expression analysis of two conditions/groups (two biological replicates per condition) was performed using the DESeq2 R package (1.16.1). DESeq2 provide statistical 
routines for determining differential expression in digital gene expression data using a model based on the negative binomial distribution. The resulting P-values were adjusted using the Benjamin and Hochberg's approach for controlling the false discovery rate. Genes with an adjusted P-value $<0.05$ found by DESeq2 were assigned as differentially expressed.

GO and KEGG enrichment analysis of differentially expressed genes. Gene Ontology (GO) enrichment analysis of differentially expressed genes was implemented by the cluster Profiler R package, in which gene length bias was corrected. GO terms with corrected P-value less than 0.05 were considered significantly enriched by differential expressed genes.

Gene Set Enrichment Analysis (GSEA) (http://www.broadinstitute.org/gsea/index.jsp) of the expression data was used to assess enrichment of the KEGG as well as the SGOC genesets.

\section{Stable gene-knockdown with short-hairpin RNAs}

We constructed pLVX-shRNAs plasmids targeting kcnj2. iBMDMs were spinfected with retrovirus encoding short-hairpin RNA for $90 \mathrm{~min}$ at $2500 \mathrm{rpm}$ and $32^{\circ} \mathrm{C}$. Forty-eight hours after infection, the cells were selected by culture with $5 \mathrm{mg} / \mathrm{mL}$ puromycin (Sigma).

shRNAs used in the study.

\section{Gene-knockdown by siRNAs}

\begin{tabular}{ll}
$k_{c n j 2-1}$ & CCCATCACTATCGTTCACGAA \\
kcnj2-2 & GCTCTTTGAAGAGAAACACTA \\
\hline
\end{tabular}

For gene-knockdown experiments, cells were transfected with siRNAs (GenePharma, Shanghai) using RNAiMAX Transfection Reagent (Thermo Fisher Scientific). Briefly, cells were seeded in 12-well plates in complete DMEM to adhere, then washed with PBS. Cells were transfected with $20 \mu \mathrm{M}$ siRNAs in $1 \mathrm{ml}$ OptiMEM (Thermo Fisher Scientific). After $6 \mathrm{~h}$, the medium was changed to DMEM and the cells were cultured for another 2 days.

siRNAs used in the study:

\begin{tabular}{|lll|}
\hline & sense(5'-3') & antisense(5'-3') \\
\hline siRNA-control & UUCUCCGAACGUGUCACGUTT & ACGUGACACGUUCGGAGAATT \\
\hline siRNA-kcnj2-1 & CCCAUCACUAUCGUUCACGAATT & UUCGUGAACGAUAGUGAUGGGTT \\
\hline siRNA-kcnj2-2 & GCUCUUUGAAGAGAAACACUATT & UAGUGUUUCUCUUCAAAGAGCTT \\
\hline
\end{tabular}

\section{Electrophysiology}


Whole-cell current recordings were performed using a HEKA EPC10 amplifier controlled with PatchMaster software (HEKA) at room temperature with a voltage ramp of $500 \mathrm{~ms}$ duration from $-120 \mathrm{mV}$ to $+60 \mathrm{mV}$ applied every $5 \mathrm{~s}$. ML133 and $\mathrm{BaCl}_{2}$ were performed when the currents reached to the steady state. Specifically, the extracellular solution (ECS) contained $135 \mathrm{mM} \mathrm{NaCl}, 5 \mathrm{mM} \mathrm{KCl}, 2 \mathrm{mM} \mathrm{CaCl} 2,1 \mathrm{mM}$ $\mathrm{MgCl} 2$ and $10 \mathrm{mM} \mathrm{HEPES}$ (adjusted to $\mathrm{pH} 7.4$ with $\mathrm{NaOH}$ ). For high potassium induced depolarization, the external solution was changed into high potassium ECS containing $50 \mathrm{mM}$ potassium L-aspartate, $90 \mathrm{mM} \mathrm{NaCl}, 2 \mathrm{mM} \mathrm{CaCl}_{2}, 1 \mathrm{mM} \mathrm{MgCl}_{2}$ and $10 \mathrm{mM}$ HEPES (adjusted to $\mathrm{pH} 7.4$ with $\mathrm{NaOH}$ ). The pipette solution contained $147 \mathrm{mM}$ potassium L-aspartate, $2 \mathrm{mM} \mathrm{MgCl}_{2}$ and $10 \mathrm{mM} \mathrm{HEPES}$ (adjusted to $\mathrm{pH} 7.3$ with $\mathrm{KOH}$ ). The membrane potential was held at $-40 \mathrm{mV}$. Glass pipettes with a resistance of $3-5 \mathrm{M} \Omega$ were used. Data were acquired at $10 \mathrm{kHz}$ and filtered offline during data analysis. The series resistance (Ra) was less than $15 \mathrm{M} \Omega$ and monitored after experiments. Change of the extracellular solution was performed using an RSC-200 system (Bio-Logic Science Instruments).

For continuously monitoring changes of membrane potential $(\mathrm{Vm})$, whole-cell configuration was adopted using current clamp $(I=0)$. we recorded a total of 3 min with or without ML133 and $5 \mathrm{~s}$ for Highpotassium $(50 \mathrm{mM})$. The membrane potential was the average $\mathrm{Vm}$ within $30 \mathrm{~s}$ of the initiation or the average $\mathrm{Vm}$ of the last $30 \mathrm{~s}$ of a total 3 minutes record.

\section{Membrane potential detection by FACS}

Mouse peritoneal macrophages were seeded into 12-well plate $\left(6 \times 10^{5} /\right.$ well $)$. Cellular membrane potential sensitive probe, $\mathrm{DiBAC}_{4}(3)$, was mixed with indicated stimuli and the peritoneal macrophages were incubated for $1 \mathrm{~h}$. Then the cells were washed with cold PBS for 3 times and FACS analysis were executed.

\section{Chromatin immunoprecipitation (ChIP) and ChIP-qPCR}

Cells were seeded at $1 \times 10^{7} /$ dish in 100 -mm dishes in complete DMEM medium (supplemented with $10 \%$ fetal bovine serum (FBS), 1\% penicillin/streptomycin) to adhere. Cells were treated with $500 \mathrm{ng} / \mathrm{ml}$ LPS in the presence or absence of compounds as indicated for 6 hours. Then experiments were performed according to the kit protocol (SimpleChIP® Plus Enzymatic Chromatin IP Kit, CST\#9005) and the final DNA samples were used for qPCR. DNA amplification for 40 cycles at $95^{\circ} \mathrm{C}$ for $30 \mathrm{~s}$ and $60^{\circ} \mathrm{C}$ for $30 \mathrm{~s}$.

ChIP primers used in the study. 


\begin{tabular}{|lll|}
\hline II-1b-ChIP-1126 & AGGGACTCCTACAGATGCAATGGT & TGCTCTGGTTGCTCTCTGTTGACT \\
\hline II-1b-ChIP-3627 & AAATCCAATGTTCTTGCCCAGCCC & TGCAAGCACTGTGAAGTGAAGCAG \\
\hline Tnf-ChIP & AAAGAAGCCGTGGGTTGGACAGAT & AGAACTGATGAGAGGGAGGCCATT \\
\hline I118-ChIP & AGGCTGATCAAGTCAACGGC & CTGATACCGGCCAGAAGGAC \\
Cxc/10-ChIP & AGAGCCTTTGGGCTTTCTCC & GGTTTGGGACTTCGCTGGTA \\
\hline
\end{tabular}

\section{Glucose uptake assay}

For in vitro glucose uptake assays, mouse peritoneal macrophages were seeded at $5 \times 10^{6} /$ well in 12 -well plates and treated as indicated. Cells were starved for $30 \mathrm{~min}$ at $37^{\circ} \mathrm{C}$ in Krebs-Ringer bicarbonate solution (KRBH, in $\mathrm{mM}: \mathrm{NaCl} 135, \mathrm{KCl} 3.6, \mathrm{NaH}_{2} \mathrm{PO} 40.5, \mathrm{CaCl}_{2}$ 1.5, $\mathrm{NaHCO}_{3}$ 2, HEPES 10 and 0.1\% BSA) after washing 3 times with cold $\mathrm{KRBH}$. Then the cells were incubated in KRBH supplemented with 2NBDG $(60 \mu \mathrm{M})$ at $37^{\circ} \mathrm{C}$ for $15 \mathrm{~min}$. After washing with cold $\mathrm{KRBH}$ for 3 times, the cells were scraped for FACS analysis. For in vivo glucose uptake assays, 8-week-old mice were intraperitoneally injected with LPS ( $1 \mathrm{mg} / \mathrm{kg}), 30 \mathrm{~min}$ later 2NBDG (500 nmol/mouse) was injected, and after another one hour, blood and peritoneal exudate cells were sequentially collected. Peripheral blood mononuclear cell (PBMC) were isolated from blood sample by Ficoll-Paque ${ }^{\mathrm{TM}}$ PLUS (GE Healthcare) according to the manufacturer's instructions. Peritoneal exudate cell (PEC) were flushed with $5 \mathrm{ml}$ cold PBS. Macrophages (CD45 ${ }^{+}$ CD $11 \mathrm{~b}^{+} \mathrm{F} 4 / 80^{+}$cells) in PECs and monocyte (CD45 ${ }^{+} \mathrm{CD} 11 \mathrm{~b}^{+}$Ly $6 \mathrm{C}^{\text {high }}$ cells) in the blood were stained with corresponding antibody for 30 min on ice. After PBS washing, FACS analysis of 2NBDG MFI was executed by BD Fortessa Multicolor flow cytometer.

\section{Calcium Flux Analysis}

Intracellular calcium flux was detected by Fluo4-AM following the manufacturer's instructions. In brief, Mouse peritoneal macrophages were seeded in 6-well plate $\left(3 \times 10^{6} /\right.$ well). Fluo4-AM and Pluronic F127 were dissolved in $\mathrm{HBSS}$ (with $\mathrm{Ca}^{2+}$ and $\mathrm{Mg}^{2+}$ ), cells were incubated at $37^{\circ} \mathrm{C}$ for $2 \mathrm{~h}$, then changed into HBSS (1\% BSA) without Fluo4 for further 30 min. After that, cells were scraped and stained with CD 45 and $\mathrm{F} 4 / 80$ in $4^{\circ} \mathrm{C}$ for 30 min for next FACS analysis. $\mathrm{CD} 45^{+} \mathrm{F} 4 / 80^{+}$macrophages were gated first and Fluo4 intensity of macrophages were recorded by BD Fortessa. Raw data was analyzed by GraphPad Prism.

\section{Membrane protein biotinylation assay}

Mouse peritoneal macrophages were seeded at $4 \times 10^{6} / \mathrm{dish}$ in $60 \mathrm{~mm}$ dishes and treated as indicated. Cells were washed three times with ice-cold PBS to remove any contaminating proteins. Then cell surface proteins were biotinylated by incubating cells with Sulfo-NHS-SS-Biotin solution on ice with a concentration of $1 \mathrm{mg} / \mathrm{ml}$ in PBS. $2 \mathrm{~h}$ later, cells were washed three times with ice-cold PBS to remove non-reacted biotinylation reagent. Alternatively, 25-50 mM Tris ( $\mathrm{pH} 8.0)$ may be used for the initial wash 
to quench any non-reacted biotinylation reagent. After being lysed and centrifuged at $12000 \mathrm{rpm}, 10 \mathrm{~min}$, the supernatant was then transferred to a $1.5 \mathrm{ml}$ microcentrifuge tube containing pre-washed streptavidin magnetic beads and incubate at $4^{\circ} \mathrm{C}$ overnights with rotation. Streptavidin magnetic beads were washed and lysed in SDS-PAGE Reducing Sample Buffer and the samples were used for western blot.

\section{Flow cytometry}

$6 \times 10^{5}$ mouse peritoneal macrophages were seeded and stimulated under the indicated conditions. Then cells were collected by cell scraper, followed by antibody staining for $30 \mathrm{~min}$ at $4{ }^{\circ} \mathrm{C}$. After washing with PBS solution to exclude nonspecific staining, the surface expression of CD98 or GLUT1 was detected by flow cytometry (ACEA NovoCyte).

\section{Statistical Analysis}

The results for q-PCR are expressed as the mean \pm SD. The mouse sepsis model and the LC/MS experiments are expressed as the mean \pm SEM and analyzed using two-tailed Student's t-test for two groups. The q-PCR results are representative of at least three independent experiments. For mouse survival rate analysis, GraphPad Prism7 was used to plot Kaplan-Meier survival curves and to compare survival using log-rank tests.

\section{Declarations}

\section{CONTACT FOR REAGENT AND RESOURCE SHARING}

Further information and requests for resources and reagents should be directed to and will be fulfilled by the Lead Contact, Di Wang (diwang@zju.edu.cn).

\section{DATA AND CODE AVAILABILITY}

The RNA-seq data in this paper have been deposited in the Gene Expression Omnibus (GEO) with accession number GEO: GSE146158.

\section{AUTHOR CONTRIBUTIONS}

W.Y., Z.W., X.Y., Z.C., K.Z., S.C., T.X., D.J., X.G., M.L., J.Z., H.F., and Q.Y. performed the experiments; X.Y., X.Z., Y.W., W.Y., and D.W. designed the research; W.Y., Z.W., and D.W. wrote the manuscript; and D.W. supervised the project.

\section{ACKNOWLEDGMENTS}

We thank Prof. Mark T. Nelson for kindly providing the $K c n j 2^{f / f}$ mice and Dr. IC Bruce for reading the manuscript. We thank Dr. Yudong Zhou for his helpful discussion. This work was supported by the National Natural Science Foundation of China (81930042, 81730047, 31670926, and 31800759 to D.W.; 81630091 and 31670840 to Y.W.), the National Key Research and Development Program of China 
(2018YFC1105203 and 2016YFC1100204). We are grateful for the support of the Metabolomics Facility at the Technology Center for Protein Sciences, Tsinghua University. Thanks for the technical support by the Core Facilities, Zhejiang University School of Medicine. This work was also supported by the Key Laboratory of Immunity and Inflammatory Diseases of Zhejiang Province.

\section{References}

1. Adamik, J., Wang, K.Z., Unlu, S., Su, A.J., Tannahill, G.M., Galson, D.L., O'Neill, L.A., and Auron, P.E. (2013). Distinct mechanisms for induction and tolerance regulate the immediate early genes encoding interleukin 1 beta and tumor necrosis factor alpha. PLoS One 8, e70622.

2. Adekola, K., Rosen, S.T., and Shanmugam, M. (2012). Glucose transporters in cancer metabolism. Curr Opin Oncol 24,650-654.

3. Billman, G.E. (1994). Role of ATP sensitive potassium channel in extracellular potassium accumulation and cardiac arrhythmias during myocardial ischaemia. Cardiovascular research 28 , 762-769.

4. Blot, V., and McGraw, T.E. (2006). GLUT4 is internalized by a cholesterol-dependent nystatin-sensitive mechanism inhibited by insulin. The EMBO journal 25, 5648-5658.

5. Broer, S., and Broer, A. (2017). Amino acid homeostasis and signalling in mammalian cells and organisms. The Biochemical journal 474, 1935-1963.

6. Chaneton, B., Hillmann, P., Zheng, L., Martin, A.C.L., Maddocks, O.D.K., Chokkathukalam, A., Coyle, J.E., Jankevics, A., Holding, F.P., Vousden, K.H., et al. (2012). Serine is a natural ligand and allosteric activator of pyruvate kinase M2. Nature 491, 458-462.

7. Chen, K., Liu, J., Liu, S., Xia, M., Zhang, X., Han, D., Jiang, Y., Wang, C., and Cao, X. (2017). Methyltransferase SETD2-Mediated Methylation of STAT1 Is Critical for Interferon Antiviral Activity. Cell 170, 492-506 e414.

8. Chisolm, D.A., and Weinmann, A.S. (2018). Connections Between Metabolism and Epigenetics in Programming Cellular Differentiation. Annual review of immunology 36, 221-246.

9. Di, A., Xiong, S., Ye, Z., Malireddi, R.K.S., Kometani, S., Zhong, M., Mittal, M., Hong, Z., Kanneganti, T.D., Rehman, J., et al. (2018). The TWIK2 Potassium Efflux Channel in Macrophages Mediates NLRP3 Inflammasome-Induced Inflammation. Immunity 49, 56-65 e54.

10. Edwards, F.R., and Hirst, G.D. (1988). Inward rectification in submucosal arterioles of guinea-pig ileum. J Physiol 404, 437-454.

11. Eil, R., Vodnala, S.K., Clever, D., Klebanoff, C.A., Sukumar, M., Pan, J.H., Palmer, D.C., Gros, A., Yamamoto, T.N., Patel, S.J., et al. (2016). Ionic immune suppression within the tumour microenvironment limits T cell effector function. Nature 537, 539-543.

12. Everts, B., Amiel, E., Huang, S.C., Smith, A.M., Chang, C.H., Lam, W.Y., Redmann, V., Freitas, T.C., Blagih, J., van der Windt, G.J., et al. (2014). TLR-driven early glycolytic reprogramming via the kinases TBK1- 
IKKvarepsilon supports the anabolic demands of dendritic cell activation. Nature immunology 15 , 323-332.

13. Eyster, C.A., Higginson, J.D., Huebner, R., Porat-Shliom, N., Weigert, R., Wu, W.W., Shen, R.F., and Donaldson, J.G. (2009). Discovery of new cargo proteins that enter cells through clathrinindependent endocytosis. Traffic 10, 590-599.

14. Feske, S., Wulff, H., and Skolnik, E.Y. (2015). Ion channels in innate and adaptive immunity. Annu Rev Immunol 33, 291-353.

15. Finder, D.R., and Hardin, C.D. (1999). Transport and metabolism of exogenous fumarate and 3phosphoglycerate in vascular smooth muscle. Mol Cell Biochem 195, 113-121.

16. Finicle, B.T., Ramirez, M.U., Liu, G., Selwan, E.M., McCracken, A.N., Yu, J., Joo, Y., Nguyen, J., Ou, K., Roy, S.G., et al. (2018). Sphingolipids inhibit endosomal recycling of nutrient transporters by inactivating ARF6. J Cell Sci 131.

17. Franchini, L., Levi, G., and Visentin, S. (2004). Inwardly rectifying K + channels influence Ca2 + entry due to nucleotide receptor activation in microglia. Cell calcium 35, 449-459.

18. Freemerman, A.J., Johnson, A.R., Sacks, G.N., Milner, J.J., Kirk, E.L., Troester, M.A., Macintyre, A.N., Goraksha-Hicks, P., Rathmell, J.C., and Makowski, L. (2014). Metabolic reprogramming of macrophages: glucose transporter 1 (GLUT1)-mediated glucose metabolism drives a proinflammatory phenotype. The Journal of biological chemistry 289, 7884-7896.

19. Gamelli, R.L., Liu, H., He, L.K., and Hofmann, C.A. (1996). Augmentations of glucose uptake and glucose transporter-1 in macrophages following thermal injury and sepsis in mice. Journal of leukocyte biology 59, 639-647.

20. Gao, X., Sanderson, S.M., Dai, Z., Reid, M.A., Cooper, D.E., Lu, M., Richie, J.P., Jr., Ciccarella, A., Calcagnotto, A., Mikhael, P.G., et al. (2019). Dietary methionine influences therapy in mouse cancer models and alters human metabolism. Nature 572, 397-401.

21. Gattlen, C., Deftu, A.F., Tonello, R., Ling, Y., Berta, T., Ristoiu, V., and Suter, M.R. (2020). The inhibition of Kir2.1 potassium channels depolarizes spinal microglial cells, reduces their proliferation, and attenuates neuropathic pain. Glia 68, 2119-2135.

22. Gido, G., Kristian, T., and Siesjo, B.K. (1997). Extracellular potassium in a neocortical core area after transient focal ischemia. Stroke 28, 206-210.

23. Goll, M.G., and Bestor, T.H. (2005). Eukaryotic cytosine methyltransferases. Annual review of biochemistry $74,481-514$.

24. Hibino, H., Inanobe, A., Furutani, K., Murakami, S., Findlay, I., and Kurachi, Y. (2010). Inwardly rectifying potassium channels: their structure, function, and physiological roles. Physiol Rev 90, 291-366.

25. Jiang, H., He, H., Chen, Y., Huang, W., Cheng, J., Ye, J., Wang, A., Tao, J., Wang, C., Liu, Q., et al. (2017). Identification of a selective and direct NLRP3 inhibitor to treat inflammatory disorders. J Exp Med $214,3219-3238$. 
26. Karkanis, T., Li, S., Pickering, J.G., and Sims, S.M. (2003). Plasticity of KIR channels in human smooth muscle cells from internal thoracic artery. Am J Physiol Heart Circ Physiol 284, H2325-2334.

27. Keller, K.E., Tan, I.S., and Lee, Y.S. (2012). SAICAR stimulates pyruvate kinase isoform M2 and promotes cancer cell survival in glucose-limited conditions. Science 338, 1069-1072.

28. Kottakis, F., Nicolay, B.N., Roumane, A., Karnik, R., Gu, H., Nagle, J.M., Boukhali, M., Hayward, M.C., Li, Y.Y., Chen, T., et al. (2016). LKB1 loss links serine metabolism to DNA methylation and tumorigenesis. Nature 539, 390-395.

29. Kumar, A., Xiao, Y.P., Laipis, P.J., Fletcher, B.S., and Frost, S.C. (2004). Glucose deprivation enhances targeting of GLUT1 to lipid rafts in 3T3-L1 adipocytes. Am J Physiol Endocrinol Metab 286, E568576.

30. Lam, D., and Schlichter, L.C. (2015). Expression and contributions of the Kir2.1 inward-rectifier K(+) channel to proliferation, migration and chemotaxis of microglia in unstimulated and antiinflammatory states. Frontiers in cellular neuroscience 9, 185.

31. Lee, J.W. (2010). Fluid and electrolyte disturbances in critically ill patients. Electrolyte Blood Press 8 , 72-81.

32. Levite, M., Cahalon, L., Peretz, A., Hershkoviz, R., Sobko, A., Ariel, A., Desai, R., Attali, B., and Lider, O. (2000). Extracellular $\mathrm{K}(+)$ and opening of voltage-gated potassium channels activate $T$ cell integrin function: physical and functional association between Kv1.3 channels and beta1 integrins. The Journal of experimental medicine 191, 1167-1176.

33. Li, J., Malaby, A.W., Famulok, M., Sabe, H., Lambright, D.G., and Hsu, V.W. (2012). Grp1 plays a key role in linking insulin signaling to glut4 recycling. Developmental cell 22, 1286-1298.

34. Locasale, J.W. (2013). Serine, glycine and one-carbon units: cancer metabolism in full circle. Nat Rev Cancer 13, 572-583.

35. Mackenzie, A.B., Chirakkal, H., and North, R.A. (2003). Kv1.3 potassium channels in human alveolar macrophages. American journal of physiology Lung cellular and molecular physiology 285, L862868.

36. Maddocks, O.D., Berkers, C.R., Mason, S.M., Zheng, L., Blyth, K., Gottlieb, E., and Vousden, K.H. (2013). Serine starvation induces stress and p53-dependent metabolic remodelling in cancer cells. Nature 493, 542-546.

37. Maddocks, O.D., Labuschagne, C.F., Adams, P.D., and Vousden, K.H. (2016). Serine Metabolism Supports the Methionine Cycle and DNA/RNA Methylation through De Novo ATP Synthesis in Cancer Cells. Mol Cell 61, 210-221.

38. Madry, C., Kyrargyri, V., Arancibia-Carcamo, I.L., Jolivet, R., Kohsaka, S., Bryan, R.M., and Attwell, D. (2018). Microglial Ramification, Surveillance, and Interleukin-1 beta Release Are Regulated by the Two-Pore Domain K(+) Channel THIK-1. Neuron 97, 299-312 e296.

39. Maldonado-Baez, L., Williamson, C., and Donaldson, J.G. (2013). Clathrin-independent endocytosis: a cargo-centric view. Exp Cell Res 319, 2759-2769. 
40. McCracken, A.N., and Edinger, A.L. (2013). Nutrient transporters: the Achilles' heel of anabolism. Trends in endocrinology and metabolism: TEM 24, 200-208.

41. Mentch, S.J., Mehrmohamadi, M., Huang, L., Liu, X., Gupta, D., Mattocks, D., Gomez Padilla, P., Ables, G., Bamman, M.M., Thalacker-Mercer, A.E., et al. (2015). Histone Methylation Dynamics and Gene Regulation Occur through the Sensing of One-Carbon Metabolism. Cell Metab 22, 861-873.

42. Mews, P., Zee, B.M., Liu, S., Donahue, G., Garcia, B.A., and Berger, S.L. (2014). Histone methylation has dynamics distinct from those of histone acetylation in cell cycle reentry from quiescence. Mol Cell Biol 34, 3968-3980.

43. Michel, V., and Bakovic, M. (2007). Lipid rafts in health and disease. Biol Cell 99, 129-140.

44. Mills, E.L., Kelly, B., Logan, A., Costa, A.S.H., Varma, M., Bryant, C.E., Tourlomousis, P., Dabritz, J.H.M., Gottlieb, E., Latorre, I., et al. (2016). Succinate Dehydrogenase Supports Metabolic Repurposing of Mitochondria to Drive Inflammatory Macrophages. Cell 167, 457-470 e413.

45. Mills, E.L., Ryan, D.G., Prag, H.A., Dikovskaya, D., Menon, D., Zaslona, Z., Jedrychowski, M.P., Costa, A.S.H., Higgins, M., Hams, E., et al. (2018). Itaconate is an anti-inflammatory metabolite that activates Nrf2 via alkylation of KEAP1. Nature 556, 113-117.

46. Miyazaki, S.I., Takahashi, K., Tsuda, K., and Yoshii, M. (1974). Analysis of non-linearity observed in the current-voltage relation of the tunicate embryo. J Physiol 238, 55-77.

47. Munoz-Planillo, R., Kuffa, P., Martinez-Colon, G., Smith, B.L., Rajendiran, T.M., and Nunez, G. (2013). $\mathrm{K}(+)$ efflux is the common trigger of NLRP3 inflammasome activation by bacterial toxins and particulate matter. Immunity 38, 1142-1153.

48. Newman, A.C., and Maddocks, O.D.K. (2017). Serine and Functional Metabolites in Cancer. Trends Cell Biol 27, 645-657.

49. O'Neill, L.A., Kishton, R.J., and Rathmell, J. (2016). A guide to immunometabolism for immunologists. Nat Rev Immunol 16,553-565.

50. Olenchock, B.A., Rathmell, J.C., and Vander Heiden, M.G. (2017). Biochemical Underpinnings of Immune Cell Metabolic Phenotypes. Immunity 46, 703-713.

51. Palsson-McDermott, E.M., Curtis, A.M., Goel, G., Lauterbach, M.A., Sheedy, F.J., Gleeson, L.E., van den Bosch, M.W., Quinn, S.R., Domingo-Fernandez, R., Johnston, D.G., et al. (2015a). Pyruvate kinase M2 regulates Hif-1alpha activity and IL-1beta induction and is a critical determinant of the warburg effect in LPS-activated macrophages. Cell Metab 21, 65-80.

52. Palsson-McDermott, E.M., Curtis, A.M., Goel, G., Lauterbach, M.A.R., Sheedy, F.J., Gleeson, L.E., van den Bosch, M.W.M., Quinn, S.R., Domingo-Fernandez, R., Johnston, D.G.W., et al. (2015b). Pyruvate Kinase M2 Regulates Hif-1alpha Activity and IL-1beta Induction and Is a Critical Determinant of the Warburg Effect in LPS-Activated Macrophages. Cell metabolism 21, 347.

53. Park, W.S., Han, J., and Earm, Y.E. (2008). Physiological role of inward rectifier K(+) channels in vascular smooth muscle cells. Pflugers Arch 457, 137-147.

54. Phan, A.T., Goldrath, A.W., and Glass, C.K. (2017). Metabolic and Epigenetic Coordination of T Cell and Macrophage Immunity. Immunity 46, 714-729. 
55. Quayle, J.M., McCarron, J.G., Brayden, J.E., and Nelson, M.T. (1993). Inward rectifier K + currents in smooth muscle cells from rat resistance-sized cerebral arteries. Am J Physiol 265, C1363-1370.

56. Ros-Baro, A., Lopez-Iglesias, C., Peiro, S., Bellido, D., Palacin, M., Zorzano, A., and Camps, M. (2001). Lipid rafts are required for GLUT4 internalization in adipose cells. Proceedings of the National Academy of Sciences of the United States of America 98, 12050-12055.

57. Sakmann, B., and Trube, G. (1984). Conductance properties of single inwardly rectifying potassium channels in ventricular cells from guinea-pig heart. J Physiol 347, 641-657.

58. Shiraki, N., Shiraki, Y., Tsuyama, T., Obata, F., Miura, M., Nagae, G., Aburatani, H., Kume, K., Endo, F., and Kume, S. (2014). Methionine metabolism regulates maintenance and differentiation of human pluripotent stem cells. Cell Metab 19, 780-794.

59. Shyh-Chang, N., Locasale, J.W., Lyssiotis, C.A., Zheng, Y., Teo, R.Y., Ratanasirintrawoot, S., Zhang, J., Onder, T., Unternaehrer, J.J., Zhu, H., et al. (2013). Influence of threonine metabolism on Sadenosylmethionine and histone methylation. Science 339, 222-226.

60. Tannahill, G.M., Curtis, A.M., Adamik, J., Palsson-McDermott, E.M., McGettrick, A.F., Goel, G., Frezza, C., Bernard, N.J., Kelly, B., Foley, N.H., et al. (2013). Succinate is an inflammatory signal that induces IL-1 beta through HIF-1alpha. Nature 496, 238-242.

61. Toyama, K., Wulff, H., Chandy, K.G., Azam, P., Raman, G., Saito, T., Fujiwara, Y., Mattson, D.L., Das, S., Melvin, J.E., et al. (2008). The intermediate-conductance calcium-activated potassium channel KCa3.1 contributes to atherogenesis in mice and humans. The Journal of clinical investigation 118 , 3025-3037.

62. Vicente, R., Escalada, A., Coma, M., Fuster, G., Sanchez-Tillo, E., Lopez-Iglesias, C., Soler, C., Solsona, C., Celada, A., and Felipe, A. (2003). Differential voltage-dependent K + channel responses during proliferation and activation in macrophages. The Journal of biological chemistry $278,46307-46320$.

63. Vodnala, S.K., Eil, R., Kishton, R.J., Sukumar, M., Yamamoto, T.N., Ha, N.H., Lee, P.H., Shin, M., Patel, S.J., Yu, Z., et al. (2019). T cell stemness and dysfunction in tumors are triggered by a common mechanism. Science 363.

64. Wagner, E.J., and Carpenter, P.B. (2012). Understanding the language of Lys36 methylation at histone H3. Nat Rev Mol Cell Biol 13, 115-126.

65. Wang, H.R., Wu, M., Yu, H., Long, S., Stevens, A., Engers, D.W., Sackin, H., Daniels, J.S., Dawson, E.S., Hopkins, C.R., et al. (2011). Selective inhibition of the K(ir)2 family of inward rectifier potassium channels by a small molecule probe: the discovery, SAR, and pharmacological characterization of ML133. ACS chemical biology 6, 845-856.

66. Wu, M., Wang, H., Yu, H., Makhina, E., Xu, J., Dawson, E.S., Hopkins, C.R., Lindsley, C.W., McManus, O.B., and Li, M. (2010). A potent and selective small molecule Kir2.1 inhibitor. In Probe Reports from the NIH Molecular Libraries Program (Bethesda (MD)).

67. Yan, Q., Lu, Y., Zhou, L., Chen, J., Xu, H., Cai, M., Shi, Y., Jiang, J., Xiong, W., Gao, J., et al. (2018). Mechanistic insights into GLUT1 activation and clustering revealed by super-resolution imaging. Proceedings of the National Academy of Sciences of the United States of America 115, 7033-7038. 
68. Yanagida, O., Kanai, Y., Chairoungdua, A., Kim, D.K., Segawa, H., Nii, T., Cha, S.H., Matsuo, H., Fukushima, J., Fukasawa, Y., et al. (2001). Human L-type amino acid transporter 1 (LAT1): characterization of function and expression in tumor cell lines. Biochimica et biophysica acta 1514, 291-302.

69. Yang, L., Xie, M., Yang, M., Yu, Y., Zhu, S., Hou, W., Kang, R., Lotze, M.T., Billiar, T.R., Wang, H., et al. (2014). PKM2 regulates the Warburg effect and promotes HMGB1 release in sepsis. Nat Commun 5, 4436.

70. Yang, M., and Vousden, K.H. (2016). Serine and one-carbon metabolism in cancer. Nat Rev Cancer 16, $650-662$.

71. Ye, C., Sutter, B.M., Wang, Y., Kuang, Z., and Tu, B.P. (2017). A Metabolic Function for Phospholipid and Histone Methylation. Mol Cell 66, 180-193 e188.

72. Ye, J., Mancuso, A., Tong, X., Ward, P.S., Fan, J., Rabinowitz, J.D., and Thompson, C.B. (2012). Pyruvate kinase $\mathrm{M} 2$ promotes de novo serine synthesis to sustain mTORC1 activity and cell proliferation. Proc Natl Acad Sci U S A 109, 6904-6909.

73. Yu, W., Wang, Z., Zhang, K., Chi, Z., Xu, T., Jiang, D., Chen, S., Li, W., Yang, X., Zhang, X., et al. (2019). One-Carbon Metabolism Supports S-Adenosylmethionine and Histone Methylation to Drive Inflammatory Macrophages. Molecular cell 75, 1147-1160 e1145.

74. Zaritsky, J.J., Eckman, D.M., Wellman, G.C., Nelson, M.T., and Schwarz, T.L. (2000). Targeted disruption of Kir2. 1 and Kir2.2 genes reveals the essential role of the inwardly rectifying $\mathrm{K}(+)$ current in $\mathrm{K}(+)$-mediated vasodilation. Circulation research 87, 160-166.

75. Zhang, W.C., Shyh-Chang, N., Yang, H., Rai, A., Umashankar, S., Ma, S., Soh, B.S., Sun, L.L., Tai, B.C., Nga, M.E., et al. (2012). Glycine decarboxylase activity drives non-small cell lung cancer tumorinitiating cells and tumorigenesis. Cell 148, 259-272.

76. Zhang, X., Cui, X., Li, X., Yan, H., Li, H., Guan, X., Wang, Y., Liu, S., Qin, X., and Cheng, M. (2019). Inhibition of Kir2.1 channel-induced depolarization promotes cell biological activity and differentiation by modulating autophagy in late endothelial progenitor cells. J Mol Cell Cardiol 127 , 57-66.

\section{Figures}


A

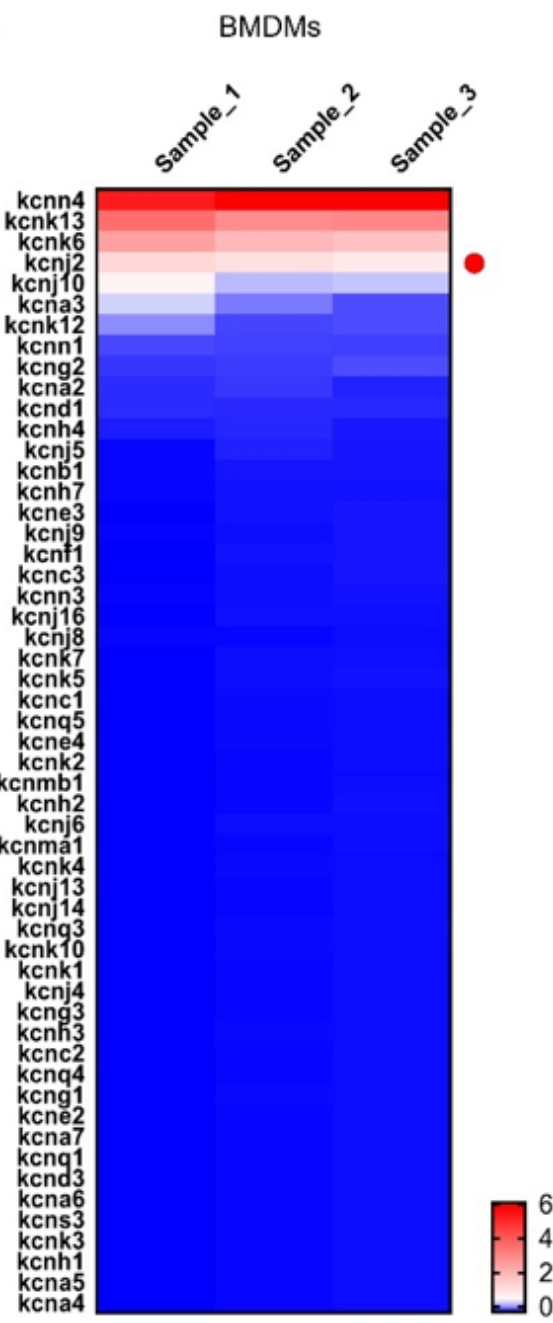

$\mathbf{F}$

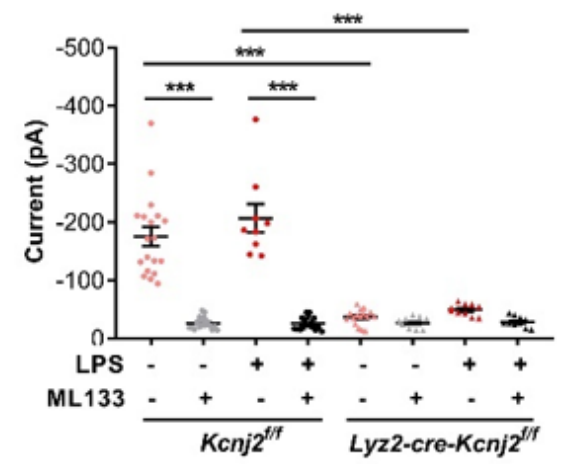

B

Kcnj2 $2^{\text {er }}$
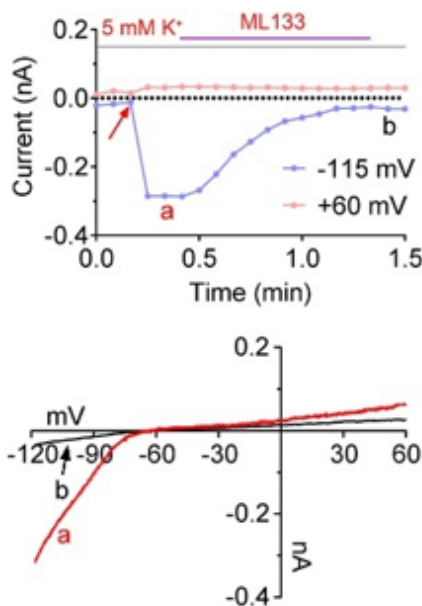

D
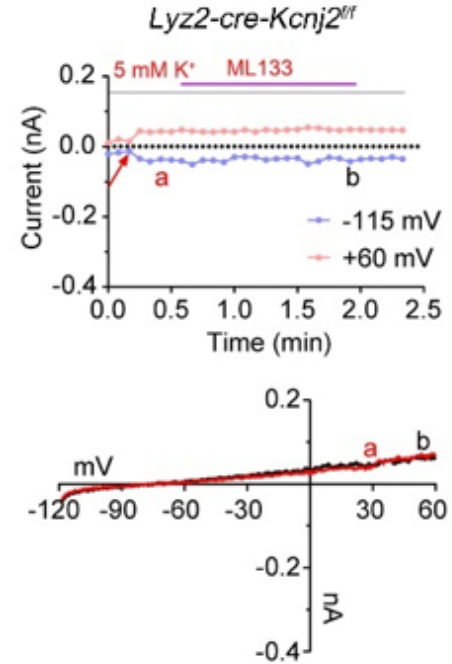

$\mathbf{G}$

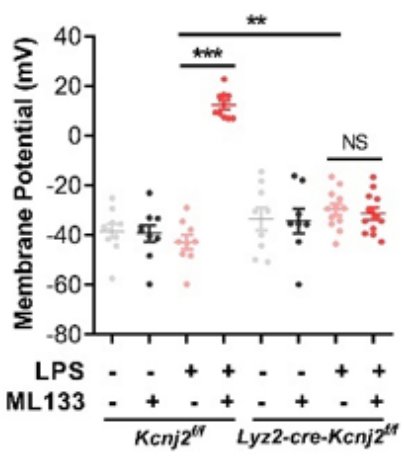

C

Kcnj2 $2^{\prime \prime}$-LPS
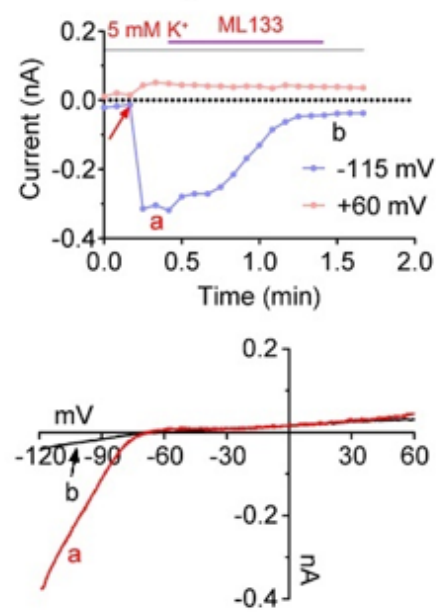

E Lyz2-cre-Kcnj2" $2^{\prime \prime}$-LPS
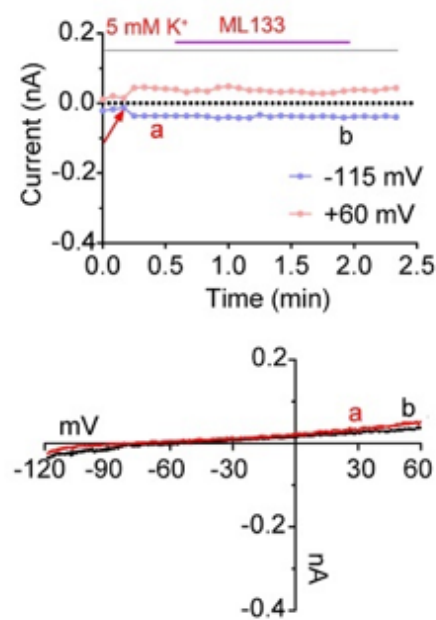

H

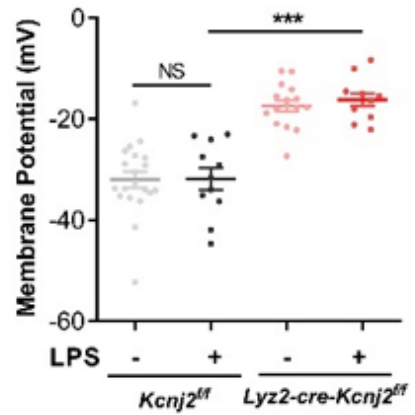

Figure 1

Kir2.1 is highly expressed and regulates the membrane potential in primary macrophages (A) Expression profile of $\mathrm{K}+$ channels in mouse bone marrow derived macrophages (BMDMs) analyzed by RNA-seq ( $n=$ 3). Count value data of different genes were standardized to Z-score by rows in IBM SPSS Statistics. (BE) Electrophysiological properties of freshly-isolated WT (B and C) and Kir2.1 knockout (D and E) mouse peritoneal macrophages using patch-clamp. Thioglycolate elicited mouse peritoneal macrophages were 
isolated and seeded onto cover slip to adhere, then subjected to patch-clamp experiments directly ( $\mathrm{B}$ and D) or following $500 \mathrm{ng} / \mathrm{ml}$ LPS treatment for $1 \mathrm{~h}$ (C and E). Whole cell patch clamp was performed and ramp from $-120 \mathrm{mV}$ to $+60 \mathrm{mV}$ in $500 \mathrm{~ms}$ every 5 seconds. In the upper panels were the time dependent current trace record at clamp voltage of $-115 \mathrm{mV}$ or $+60 \mathrm{mV}$. The red arrow indicates the initiation of whole cell record. Point ' $a$ ' indicates the representative steady state of record with $5 \mathrm{mM}$ extracellular $\mathrm{K}+$. Point ' $b$ ' indicate the representative steady state of record with $50 \mu \mathrm{M} \mathrm{ML133} \mathrm{in} 5 \mathrm{mM}$ extracellular $\mathrm{K}+$. The lower panels were the I-V curve of the corresponding point in the upper panels. (F) Statistics of current amplitude recorded at clamp voltage of $-115 \mathrm{mV}$. Macrophages were treated and clamped as described above (Kcnj2f/f, $n=19,18,9,17$ respectively; Lyz2-cre-Kcnj2f/f, $n=16,9,10,10$ respectively; mean $\pm S E M)$. (G) Statistics of membrane potential recorded at 3 minutes after record initiation (Kcnj2f/f, $n=10,9,9,9$ respectively; Lyz2-cre-Kcnj2f/f, $n=9,8,12,12$ respectively; mean $\pm S E M)$. (H) Statistics of membrane potential recorded at 30 seconds after record initiation $(K c n j 2 f / f, n=20,11$ respectively; Lyz2-cre-Kcnj2f/f, $n=16,11$ respectively; mean $\pm S E M)$. ${ }^{\star} p<0.05,{ }^{\star \star} p<0.01,{ }^{\star \star \star} p<0.001$. two-tailed unpaired Student's t-test. See also Figure $\mathrm{S} 1$. 
A

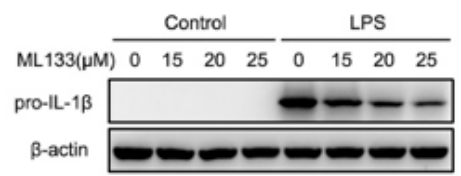

B

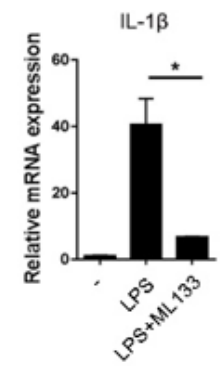

D

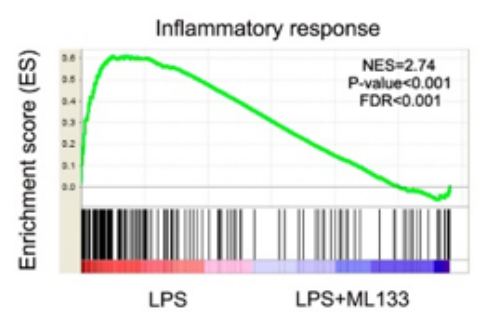

G

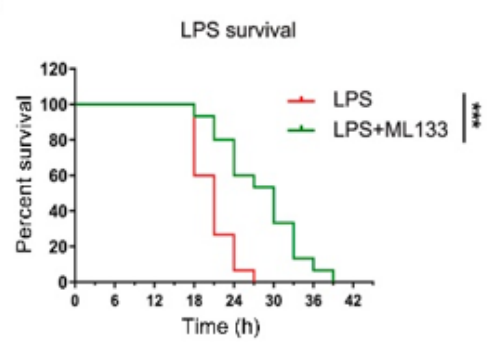

J

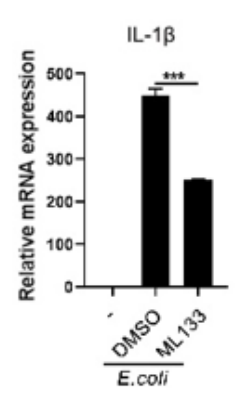

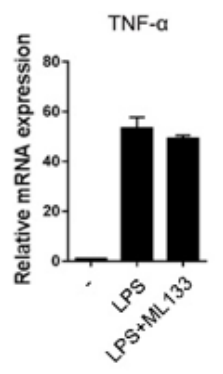

E

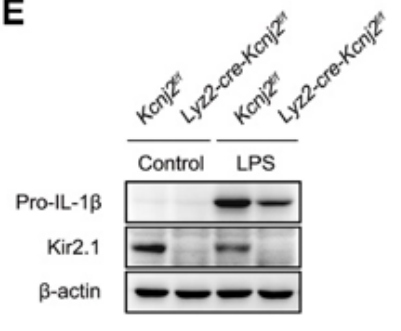

H
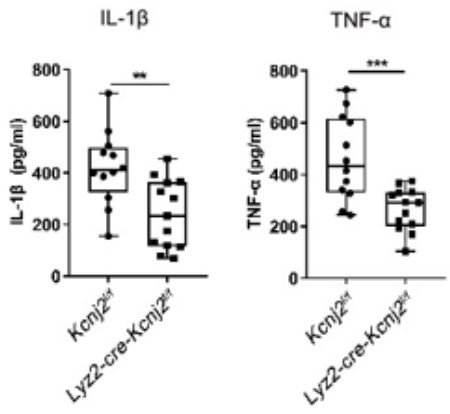

F

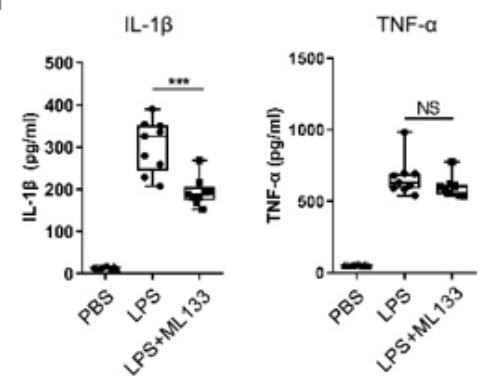

I

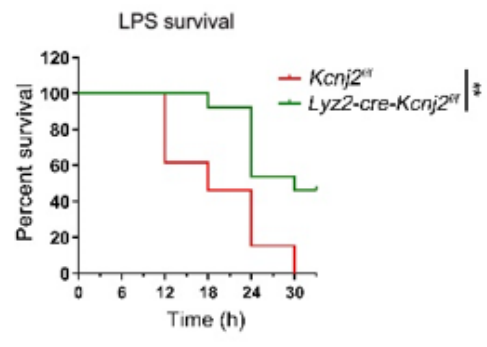

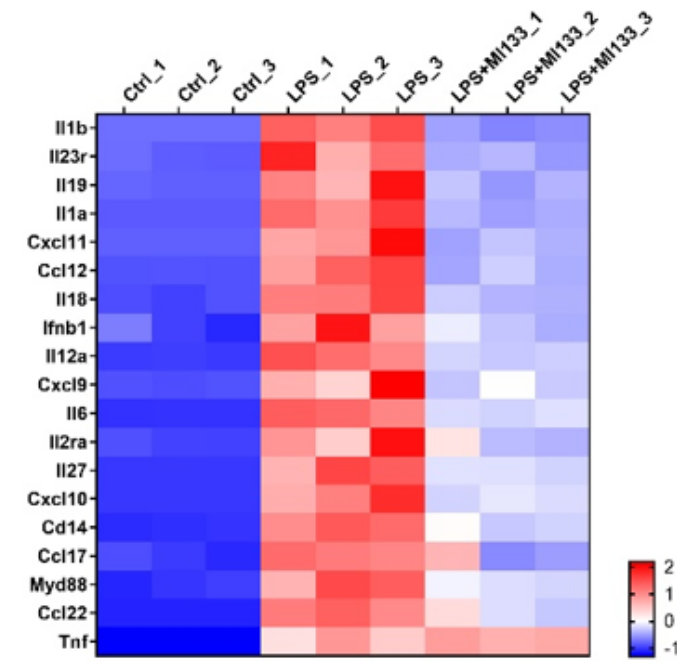

K
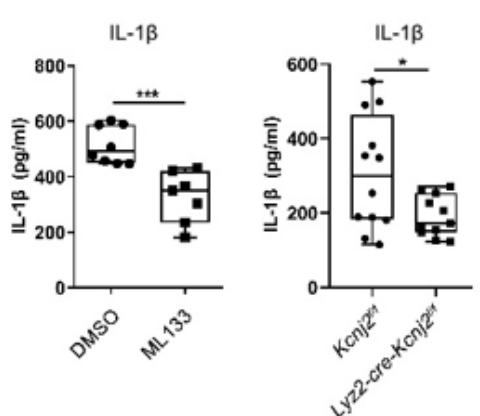

L

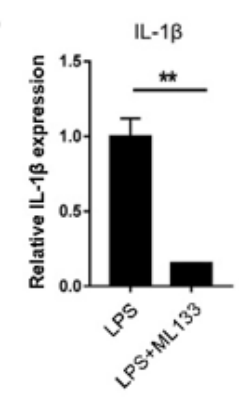

Figure 2

Kir2.1 promotes LPS- and infection-induced inflammatory cytokines and pathological inflammation (A) Pro-IL-1 $\beta$ expression levels detected by western blot. Mouse peritoneal macrophages were treated with $500 \mathrm{ng} / \mathrm{ml}$ LPS for $6 \mathrm{~h}$ in the presence or absence of different concentrations of ML133. (B) IL-1 $\beta$ and TNF-a transcription levels detected by qPCR. Mouse peritoneal macrophages treated with $500 \mathrm{ng} / \mathrm{ml}$ LPS for $6 \mathrm{~h}$ in the presence or absence of ML133 (25 $\mu \mathrm{M})$, then mRNA expression levels were analyzed by 
qPCR (mean $\pm \mathrm{SD}$ ). (C and D) RNA-seq analysis of inflammatory genes. BMDMs were treated with 500 $\mathrm{ng} / \mathrm{ml}$ LPS for $6 \mathrm{~h}$ in the presence or absence of ML133 $(25 \mu \mathrm{M})$, then RNA was extracted for RNAsequencing. Heatmap of inflammatory genes (C) and GSEA analysis showing enrichment of the inflammatory response genes (D). NES, normalized enrichment score; FDR, false discovery rate. $(n=3)(E)$ Pro-IL-1 $\beta$ expression levels detected by western blot. Mouse peritoneal macrophages from control and Lyz2-cre-Kcnj2f/f mice were treated with $500 \mathrm{ng} / \mathrm{ml}$ LPS for $6 \mathrm{~h}$, then cells were lysed for western blot. (F) IL-1 $\beta$ and TNF-a levels in serum from sepsis mice. 8-week-old mice were intraperitoneally injected with LPS $(25 \mathrm{mg} / \mathrm{kg})$ in the presence or absence of ML133 $(30 \mathrm{mg} / \mathrm{kg})$ for $4 \mathrm{~h}$, then mice were sacrificed and IL-1 $\beta$ and TNF-a levels in serum were measured by ELISA ( $n=9$, mean $\pm S E M)$. (G) Survival rates of mice sepsis model. 8-week-old mice challenged with LPS $(20 \mathrm{mg} / \mathrm{kg})$ with or without ML133 $(30 \mathrm{mg} / \mathrm{kg})$ at the same time, then survival rates were analyzed ( $n=15$, log rank test [Mantel-Cox]). (H) IL-1 $\beta$ and TNF- $a$ levels in serum from sepsis mice. 8 week old $\mathrm{Kcnj} 2 \mathrm{f} / \mathrm{f}$ and Lyz2-cre-Kcnj2f/f mice were intraperitoneally injected with LPS $(25 \mathrm{mg} / \mathrm{kg})$ for $4 \mathrm{~h}$, then mice were sacrificed and IL-1 $\beta$ and TNF-a levels in serum were measured by ELISA (Kcnj2f/f , $n=12$; Lyz2-cre-Kcnj2f/f, $n=13$; mean $\pm S E M$ ). (I) Survival rates of mice sepsis model. 8-week-old Kcnj2f/f and Lyz2-cre-Kcnj2f/f mice were challenged with LPS $(20 \mathrm{mg} / \mathrm{kg})$, then survival rates were analyzed ( $n=13$; log rank test [Mantel-Cox]). (J) IL-1 $\beta$ transcription levels detected by qPCR. Peritoneal macrophages infected with $5 \times 106$ E.coli or salmonella SL1344 for $6 \mathrm{~h}$ in the presence or absence of ML133 $(25 \mu \mathrm{M})$, then mRNA expression levels were analyzed by qPCR (mean \pm SD). (K) IL-1 $\beta$ levels in serum from sepsis mice. 8 week old WT or Lyz2-cre-Kcnj2f/f mice were intraperitoneally infected with E.coli (about 1×107 per mice)in the presence or absence of ML133 $(30 \mathrm{mg} / \mathrm{kg})$ for $4 \mathrm{~h}$, then mice were sacrificed and IL-1 $\beta$ levels in serum were measured by ELISA (DMSO, $n=8 ; M L 133, n=7 ; K c n j 2 f / f$, $n=12$, Lyz2-cre-Kcnj2f/f, $n=11$; mean $\pm S E M)$. (L) IL-1 $\beta$ levels in the supernatant of cultured synovial fluid cells from one gouty patient. Synovial fluid cells treated with LPS $(100 \mathrm{ng} / \mathrm{ml})$ in the presence or absence of ML133 $(25 \mu \mathrm{M})$ for $12 \mathrm{~h}$, then IL-1 $\beta$ levels in the supernatant were analyzed by ELISA. Data are representative of two gouty patients (mean $\pm S D$ ). ${ }^{*} p<0.05,{ }^{*} p<<0.01,{ }^{* \star} p<0.001$. (two-tailed unpaired Student's t-test). The qPCR and western blot data are representative of three independent experiments. See also Figure S2. 

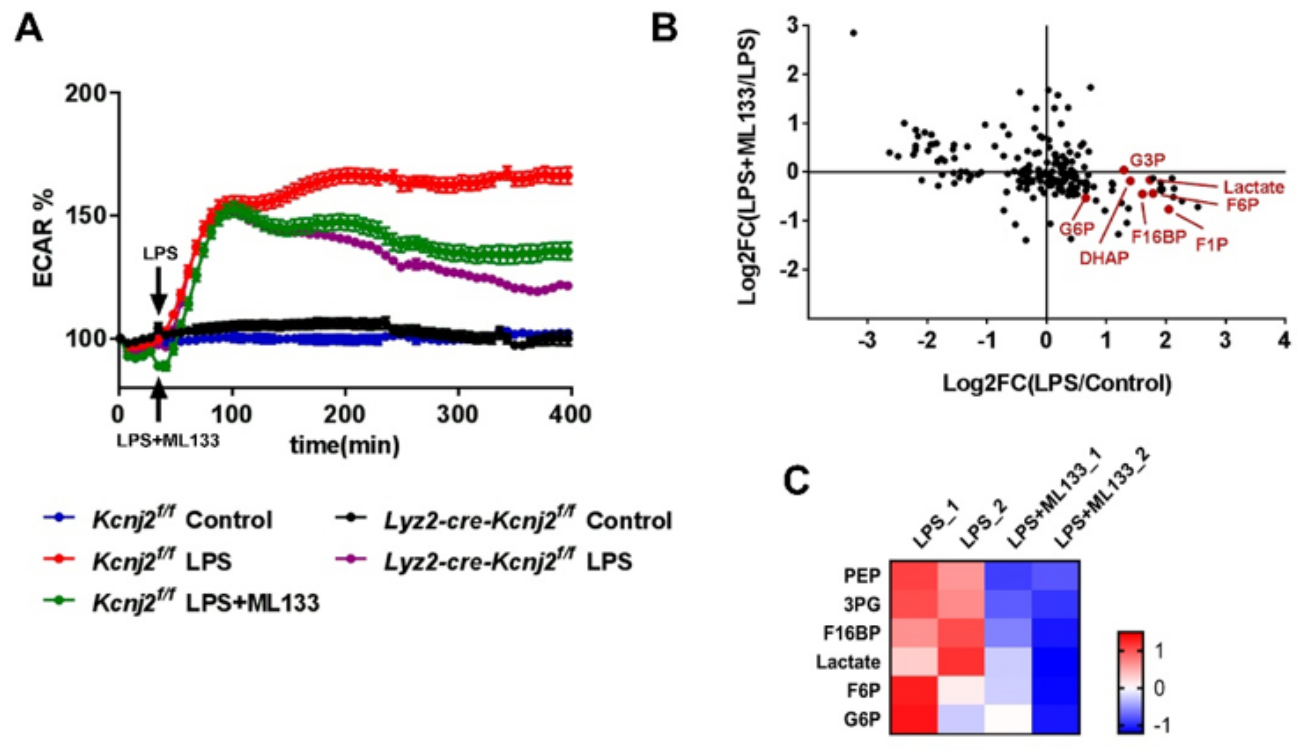

D

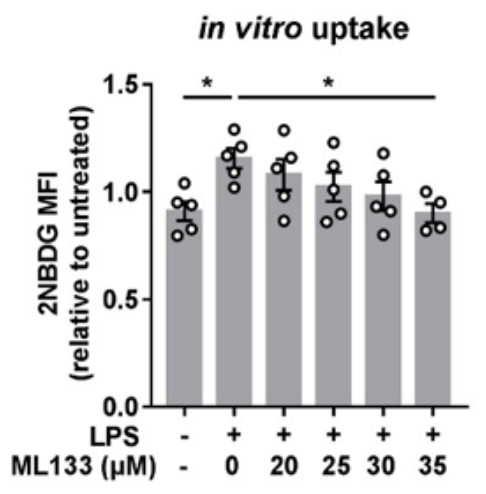

$\mathbf{F}$

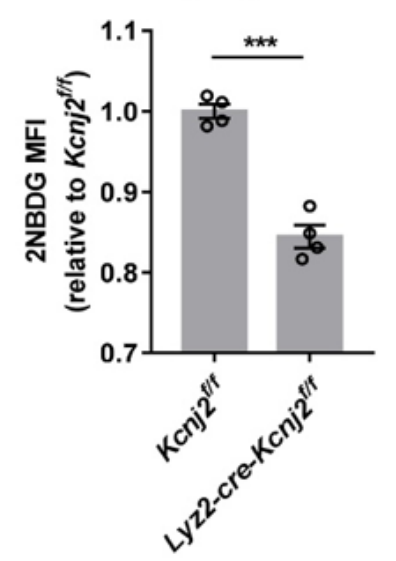

E

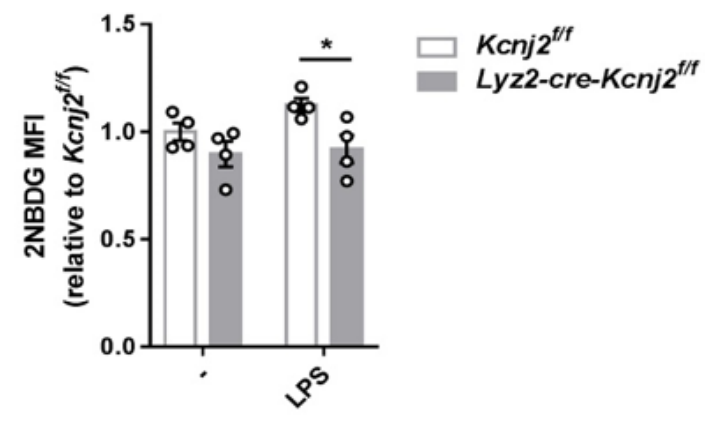

G monocytes in PBMCs

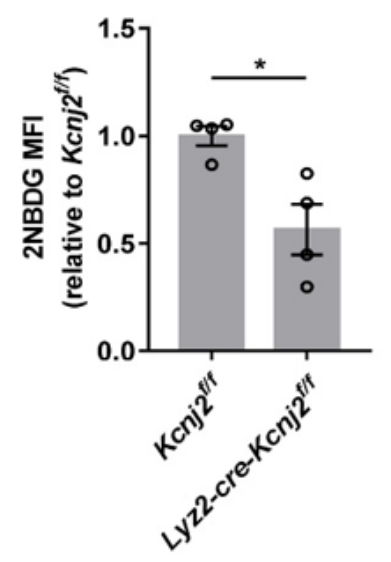

\section{Figure 3}

Kir2.1 promotes glucose uptake and consumption in inflammatory macrophages (A) Extracellular acidification rate (ECAR) analyzed by Seahorse. BMDMs from control and Lyz2-cre-Kcnj2f/f mice were treated with $500 \mathrm{ng} / \mathrm{ml}$ LPS in the presence or absence of ML133 $(25 \mu \mathrm{M})$, then ECAR were dynamically detected by Seahorse. (B) Metabolites of glycolysis identified in unbiased metabolomics. Mouse peritoneal macrophages were treated with $500 \mathrm{ng} / \mathrm{ml}$ LPS in the presence or absence of ML133 $(25 \mu \mathrm{M})$ 
for $6 \mathrm{~h}$, then cell metabolites were extracted and analyzed by LC-MS $(n=6)$. (C) Metabolites of glycolysis identified in targeted metabolomics. Mouse peritoneal macrophages were treated with $500 \mathrm{ng} / \mathrm{ml}$ LPS in the presence or absence of ML133 $(25 \mu \mathrm{M})$ for $6 \mathrm{~h}$, then cell metabolites were extracted and analyzed by LC-MS ( $n=2)$. (D) In vitro glucose uptake assay. Mouse peritoneal macrophages treated with $500 \mathrm{ng} / \mathrm{ml}$ LPS in the presence or absence of different concentrations of ML133 for 30 minutes, then cells were subjected to glucose uptake assay (mean $\pm S D$ ). (E) In vitro glucose uptake assay. Mouse peritoneal macrophages from control and Lyz2-cre-Kcnj2f/f mice were treated with $500 \mathrm{ng} / \mathrm{ml} \mathrm{LPS} \mathrm{for} 30$ minutes, then cells were subjected to glucose uptake assay (mean $\pm S D$ ). ( $F$ and $G)$ In vivo glucose uptake assay. Control and Lyz2-cre-Kcnj2f/f mice were intraperitoneally injected with LPS (1 mg/kg) for $30 \mathrm{~min}$ followed by intraperitoneally injected with 2NBDG for $1 \mathrm{~h}$. Then glucose uptake by inflammatory macrophages (CD45+ CD11b+ F4/80+) in PECs and monocytes (CD45+ CD11b+ Ly6Chigh) in PBMCs were reflected by 2 NBDG MFI by FACS $\left(n=4\right.$, mean \pm SEM). ${ }^{*}<<0.05,{ }^{*} p<0.01$, ${ }^{* \star} p<0.001$ (two-tailed unpaired Student's t-test,). The ECAR and glucose uptake data are representative of three independent experiments. See also Figure S3. 
A

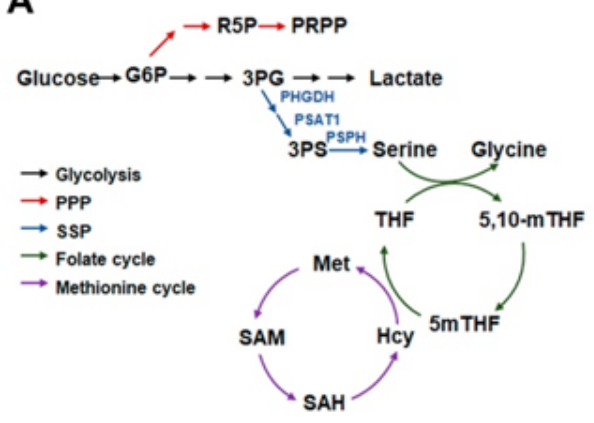

D

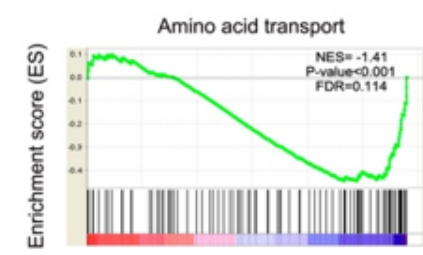

LPS LPS+ML133

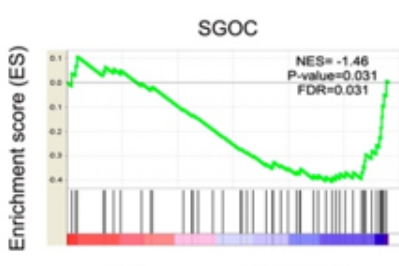

LPS LPS+ML133
B

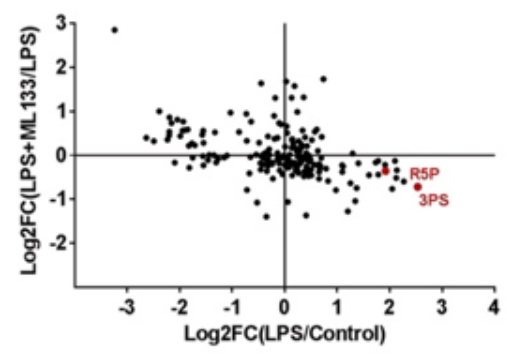

C

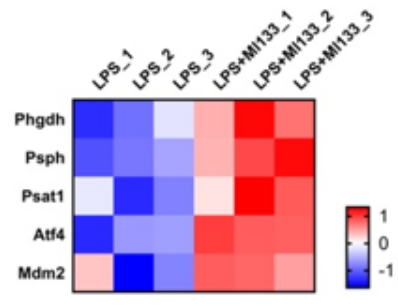

E

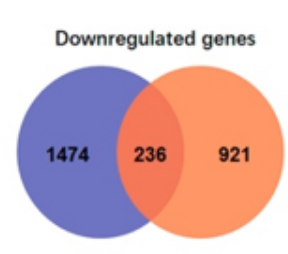

Upregulated genes

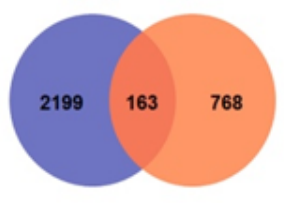

- $K O+L P S / W T+L P S$

- LPS+ML133/LPS
F
Overlapped downregulated genes

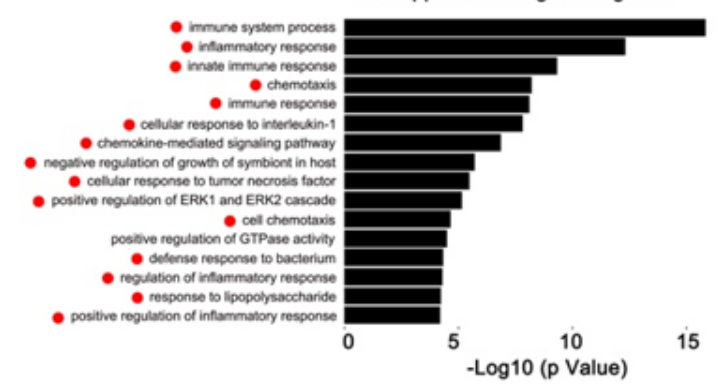

Overlapped upregulated genes

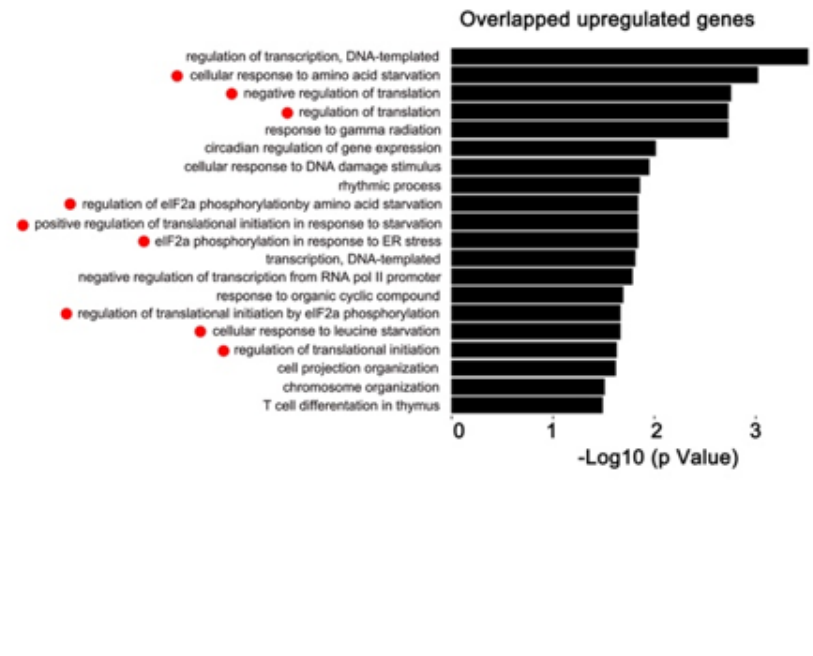

I

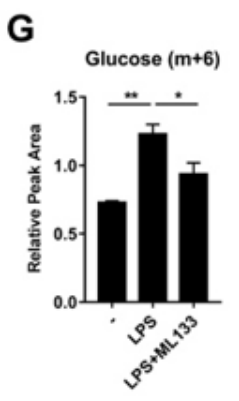

H
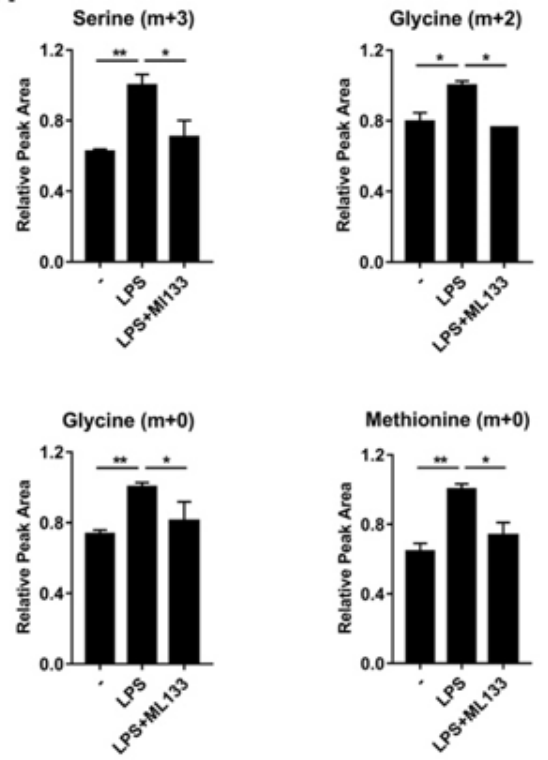

\section{Figure 4}

Kir2.1 loss-of-function leads to blunted glycolysis offshoots and SGOC metabolism in LPS-stimulated macrophages (A) Schematic of glycolysis, the PPP, SSP, folate cycle, and methionine cycle. Enzymes of the three-step SSP are highlighted in blue. (B) Metabolites of 3PS and R5P identified in unbiased metabolomics. Mouse peritoneal macrophages were treated with $500 \mathrm{ng} / \mathrm{ml}$ LPS in the presence or absence of ML133 (25 $\mu \mathrm{M})$ for $6 \mathrm{~h}$, then cell metabolites were extracted and analyzed by LC-MS (n=6). (C) 
Heatmap of RNA-seq analysis of enzyme genes and master regulators for the SSP. BMDMs were treated with $500 \mathrm{ng} / \mathrm{ml}$ LPS in the presence or absence of ML133 $(25 \mu \mathrm{M})$ for $6 \mathrm{~h}$, then mRNA was extracted for RNA-sequencing ( $n=3)$. (D) GSEA of amino acid transport and SGOC metabolism. BMDMs were treated with $500 \mathrm{ng} / \mathrm{ml}$ LPS in the presence or absence of ML133 $(25 \mu \mathrm{M})$ for $6 \mathrm{~h}$, then mRNA was extracted for RNA-sequencing. Then genes expression was analyzed. NES, normalized enrichment score. FDR, false discovery rate. ( $E$ and $F)$ Genes expression levels analyzed by RNA-sequencing. Analysis of overlapped genes downregulated and upregulated by both ML133 treatment and Kir2.1-deficiency in LPS-primed BMDMs (E), and pathway enrichment analysis of these genes $(F)$. (G - I) Mass isotopomer distribution analysis of metabolites derived from glucose. Mouse peritoneal macrophages treated with $500 \mathrm{ng} / \mathrm{ml}$ LPS for $6 \mathrm{~h}$ with or without ML133 $(25 \mu \mathrm{M})$ in medium containing U-[13C]-glucose $(25 \mathrm{mM})$, then metabolites were extracted and the labeled glucose $(\mathrm{G})$, serine, glycine $(\mathrm{H})$, unlabeled serine, glycine, and methionine (I) were analyzed by LC-MS ( $n=5$, mean \pm SEM). ${ }^{*} p<0.05,{ }^{* \star} p<0.01$ (two-tailed unpaired Student's t-test). See also Figure S4. 
A

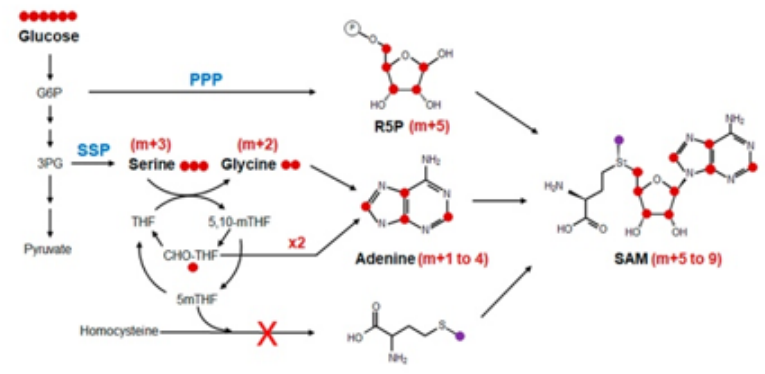

C

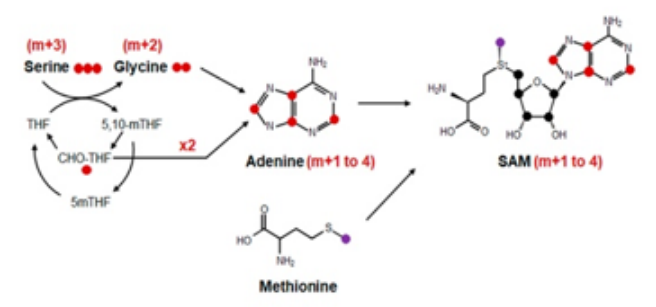

$\mathbf{F}$

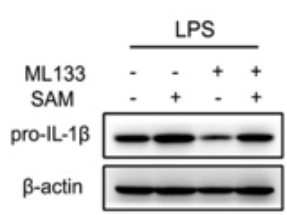

I

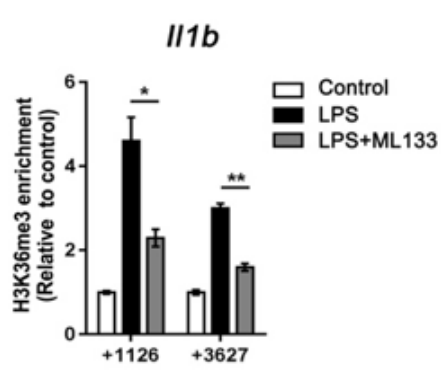

B
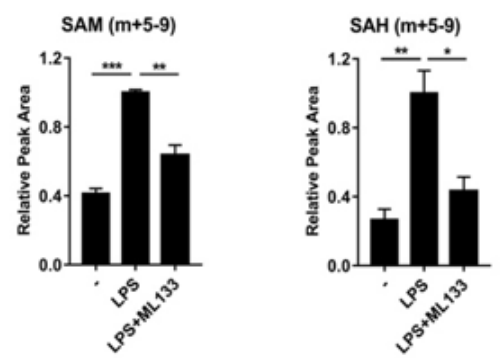

D

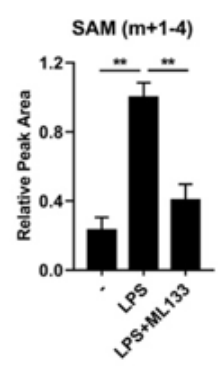

E
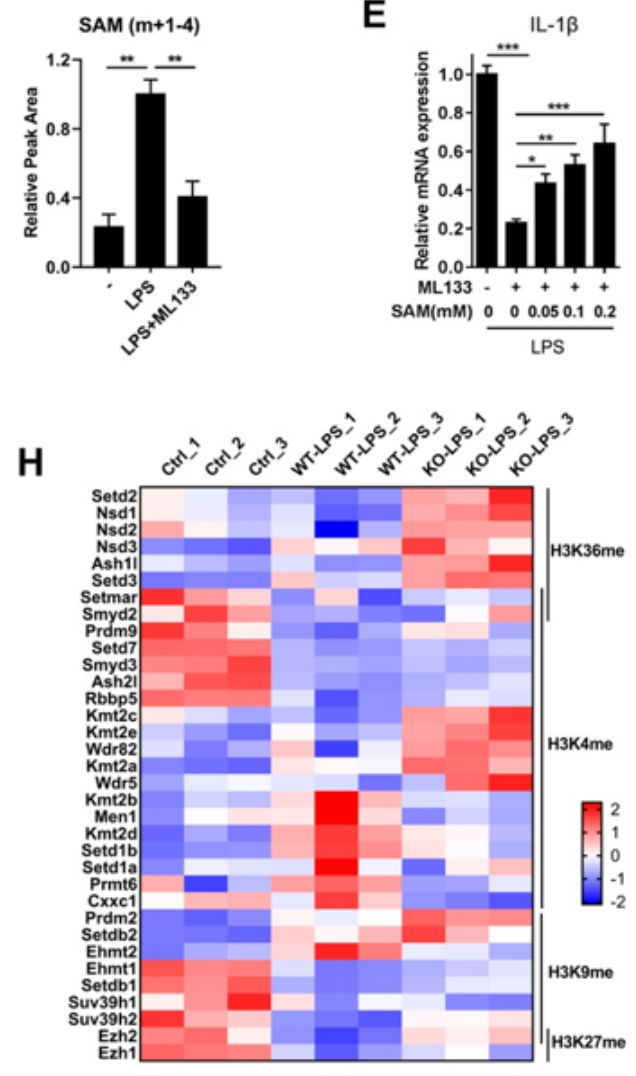

$\mathbf{J}$
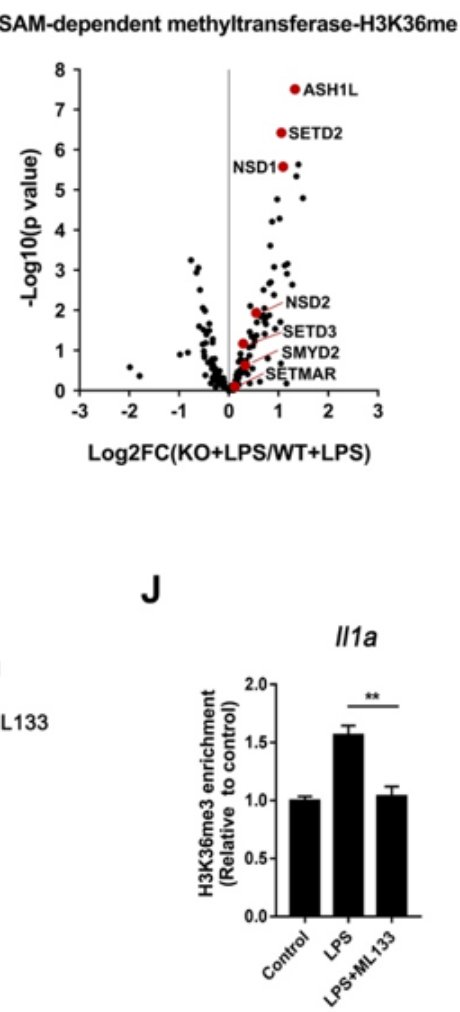

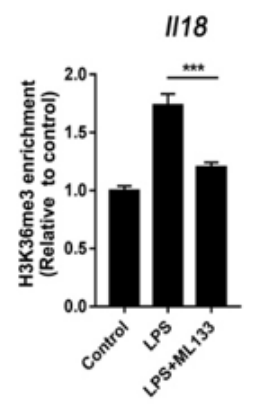

Cxcl10

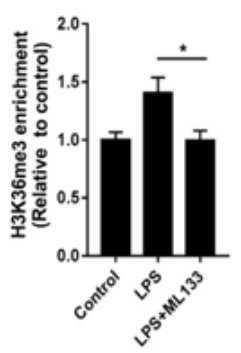

\section{Figure 5}

Kir2.1 supports S-adenosylmethionine generation and configures histone methylation in inflammatory macrophages (A) Schematic of derivation and contribution of glucose-derived carbon atoms to SAM synthesis. (B) Mass isotopomer distribution analysis of SAM and SAH derived from glucose. Mouse peritoneal macrophages treated with $500 \mathrm{ng} / \mathrm{ml}$ LPS for $6 \mathrm{~h}$ with or without ML133 $(25 \mu \mathrm{M})$ in medium containing U-[13C]-glucose (25 mM), then metabolites were extracted and the labeled SAM and S- 
adenosylhomocysteine (SAH) were analyzed by LC-MS ( $n=5$, mean \pm SEM). (C) Schematic of derivation and contribution of serine-derived carbon atoms to SAM synthesis. (D) Mass isotopomer distribution analysis of SAM derived from serine. Mouse peritoneal macrophages treated with $500 \mathrm{ng} / \mathrm{ml} \mathrm{LPS}$ for $6 \mathrm{~h}$ with or without ML133 $(25 \mu \mathrm{M})$ in medium containing U-[13C]-serine $(0.4 \mathrm{mM})$, then metabolites were extracted and the labeled SAM were analyzed by LC-MS $(n=5$, mean $\pm S E M)$. (E and F) IL-1 $\beta$ mRNA transcription analyzed by qPCR $(\mathrm{E})$ and pro-IL-1 $\beta$ protein expression analyzed by western blot $(\mathrm{F})$ in 500 $\mathrm{ng} / \mathrm{ml}$ LPS-treated mouse peritoneal macrophages for $6 \mathrm{~h}$ in the presence of ML133 $(25 \mu \mathrm{M})$ with or without different concentrations of SAM (mean $\pm S D$ ). ( $(G$ and $H)$ Volcano plot $(G)$ and heatmap $(H)$ analysis of gene expression of SAM-dependent methyltransferase by RNA-seq. BMDMs were treated with $500 \mathrm{ng} / \mathrm{ml}$ LPS for $6 \mathrm{~h}$, then mRNA were extracted for RNA-sequencing and the expression levels of methyltransferase genes for H3K36me (highlighted in red in G) (Wagner and Carpenter, 2012) among 183 annotated SAM-dependent methyltransferase genes (Kottakis et al., 2016) were analyzed. (I and J) ChIPqPCR analysis of H3K36me3 enrichment in the $\|1 \mathrm{~b}(\mathrm{I})\| ,1 \mathrm{a}, \| 18$, and $\mathrm{CxCl} 10(\mathrm{~J})$ genes. Mouse peritoneal macrophages were treated with $500 \mathrm{ng} / \mathrm{ml}$ LPS in the presence or absence of ML133 (25 $\mu \mathrm{M})$ for $6 \mathrm{~h}$, then cells were subjected to ChIP-qPCR analysis (mean \pm SD). ${ }^{\star} p<0.05$, ${ }^{*} p<0.01$, ${ }^{* \star} p<0.001$ (two-tailed unpaired Student's t-test). The ChIP-qPCR data are representative of three independent experiments. See also Figure S5. 
A

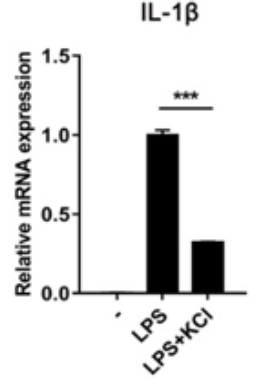

D

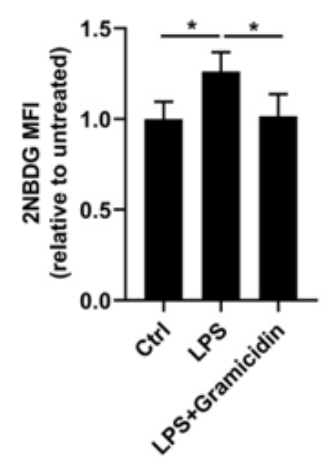

F

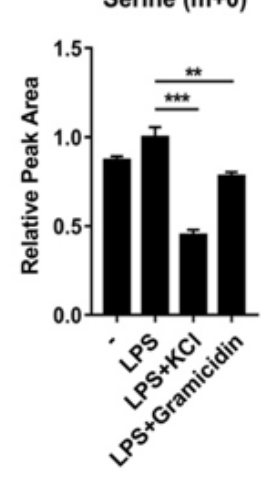

H

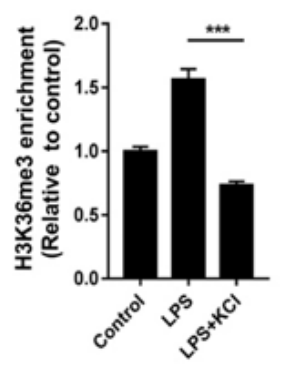

TNF- $\alpha$

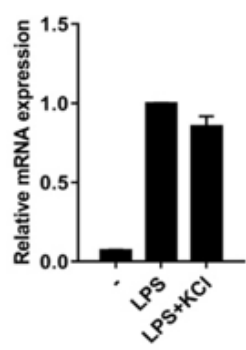

B

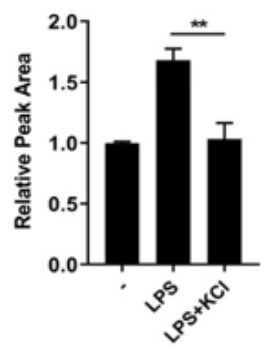

C

IL-1 $\beta$

TNF- $\alpha$

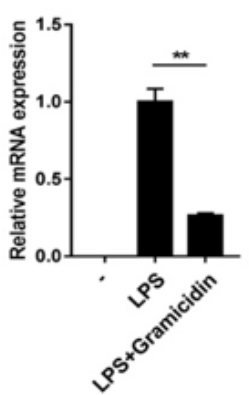

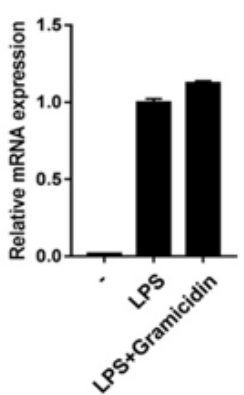

SAM $(m+5-9)$
E

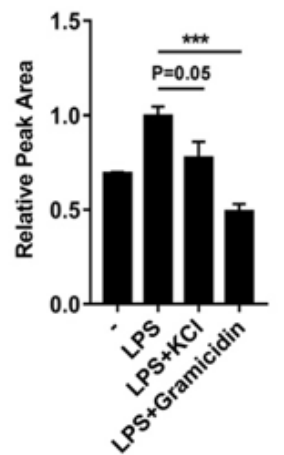

ATP $(m+5-9)$

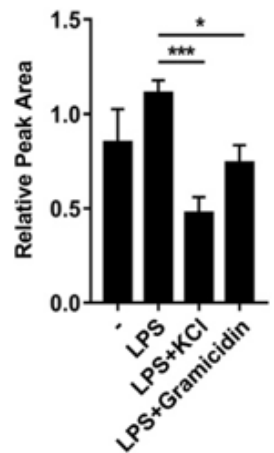

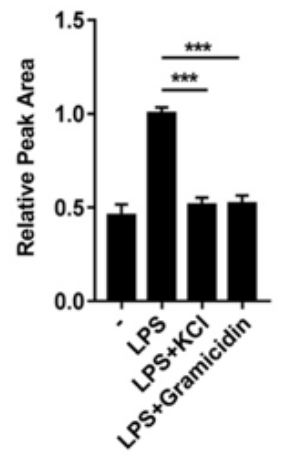

G

II1b
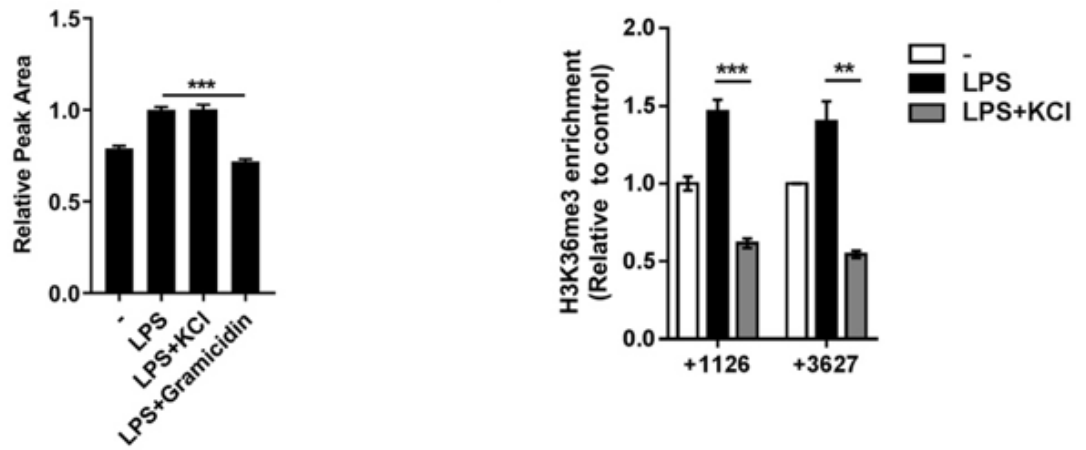

II18

Cxcl10
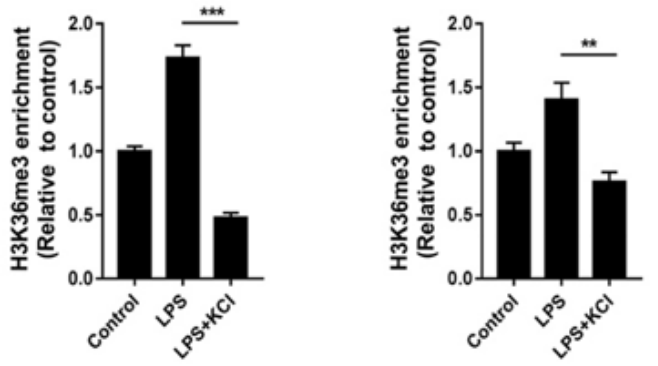

Figure 6

Kir2.1-mediated regulation of membrane potential orchestrates metabolic-epigenetic reprogramming in inflammatory macrophages (A) IL-1 $\beta$ and TNF-a transcription levels detected by qPCR. Mouse peritoneal macrophages treated with $500 \mathrm{ng} / \mathrm{ml}$ LPS for $6 \mathrm{~h}$ in the presence of physiological or elevated [K+]e (50 $\mathrm{mM}$ ), then mRNA expression levels were analyzed by qPCR (mean \pm SD). (B) Mass isotopomer distribution analysis of $\mathrm{m}+6$ glucose. Mouse peritoneal macrophages treated with $500 \mathrm{ng} / \mathrm{ml}$ LPS for $6 \mathrm{~h}$ 
in the presence of physiological or elevated $[\mathrm{K}+] \mathrm{e}(50 \mathrm{mM})$ in medium containing U-[13C]-glucose (25 $\mathrm{mM})$, then metabolites were extracted and the labeled $m+6$ glucose were analyzed by LC-MS. $(n=5$, mean \pm SEM). (C) IL-1 $\beta$ and TNF- $\alpha$ transcription levels detected by qPCR. Mouse peritoneal macrophages treated with $500 \mathrm{ng} / \mathrm{ml}$ LPS for $6 \mathrm{~h}$ in the presence or absence of gramicidin $(2 \mu \mathrm{M})$, then mRNA expression levels were analyzed by qPCR. (mean \pm SD). (D) In vitro glucose uptake assay. Mouse peritoneal macrophages treated with $500 \mathrm{ng} / \mathrm{ml}$ LPS for 30 minutes in the presence or absence of $2 \mu \mathrm{M}$ gramicidin, then cells were subjected to glucose uptake assay. (mean \pm SD). (E and F) Mass isotopomer distribution analysis of metabolites derived from glucose. Mouse peritoneal macrophages treated with $500 \mathrm{ng} / \mathrm{ml}$ LPS for $6 \mathrm{~h}$ in the presence of physiological or elevated [K+]e $(50 \mathrm{mM})$ or gramicidin $(2 \mu \mathrm{M})$ in medium containing $\mathrm{U}-[13 \mathrm{C}]$-glucose $(25 \mathrm{mM})$, then metabolites were extracted and the labeled metabolites were analyzed by LC-MS. ( $n=5$, mean \pm SEM). ( $G$ and H) ChIP-qPCR analysis of H3K36me3 enrichment in the $\|1 \mathrm{~b}(\mathrm{G})\| ,1 \mathrm{a}, \| 18$, and $\mathrm{CxCl} 10(\mathrm{H})$ genes. Mouse peritoneal macrophages were treated with $500 \mathrm{ng} / \mathrm{ml}$ LPS in the presence of physiological or elevated [K+]e $(50 \mathrm{mM})$ for $6 \mathrm{~h}$, then cells were subjected to ChIP-qPCR analysis. ${ }^{\star} p<0.05,{ }^{\star \star} p<0.01,{ }^{\star \star *} p<0.001$ (two-tailed unpaired Student's t-test). The data of qPCR, and ChIP-qPCR are representative of three independent experiments. See also Figure S6. 
A

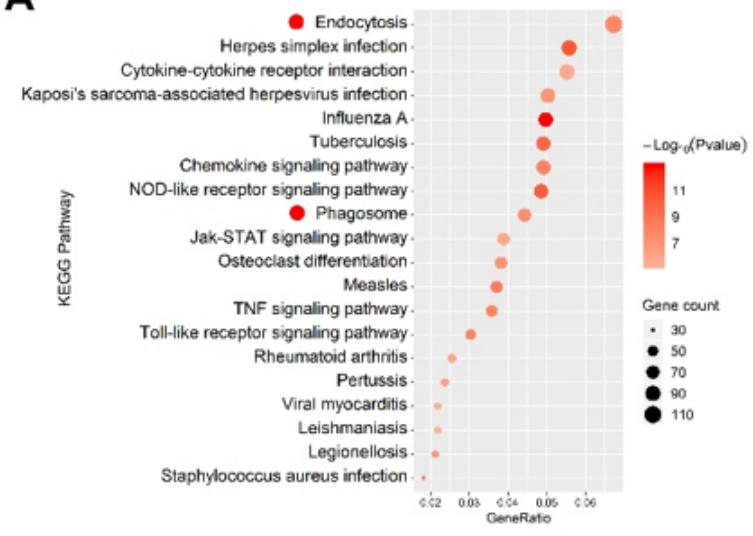

C

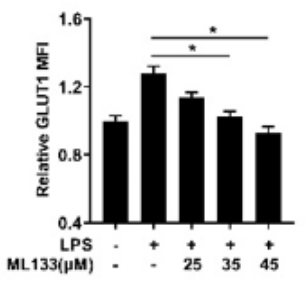

E
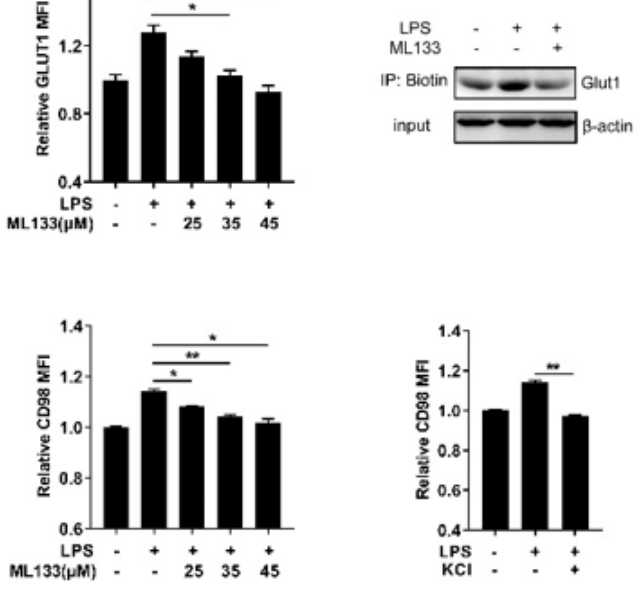

B

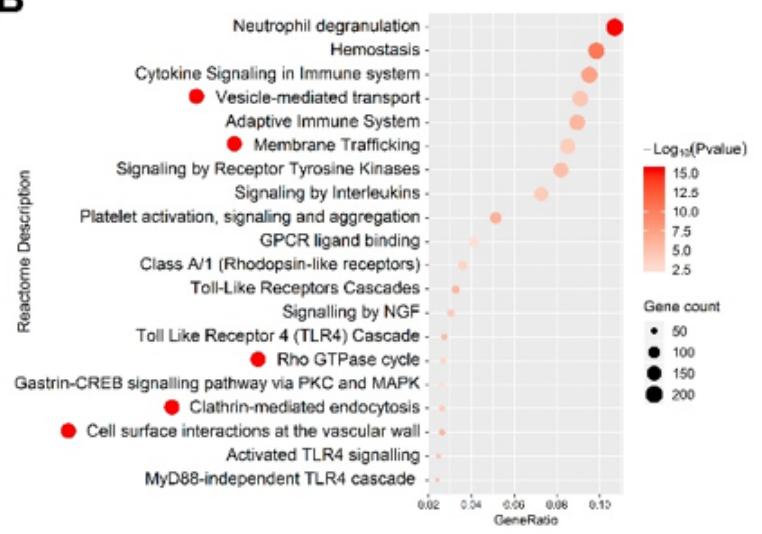

D

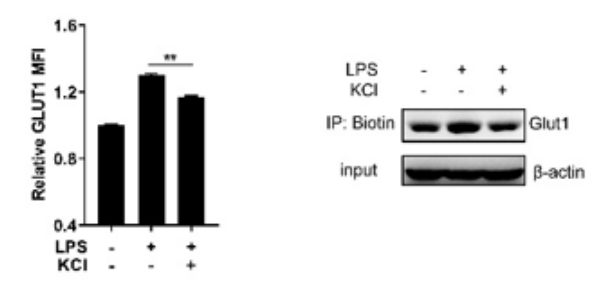

$\mathbf{F}$

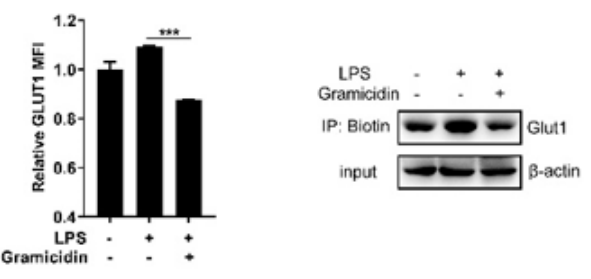

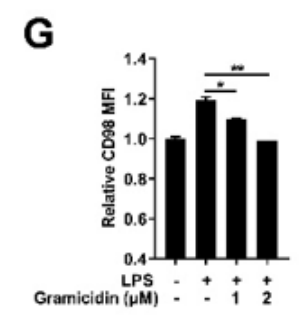

H
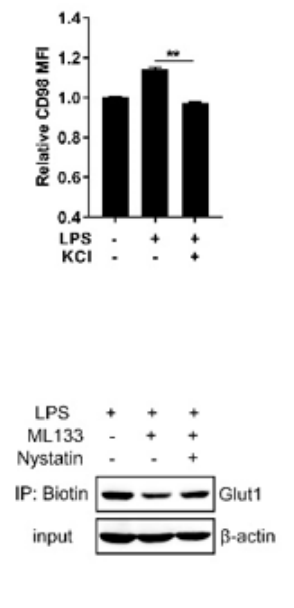

I
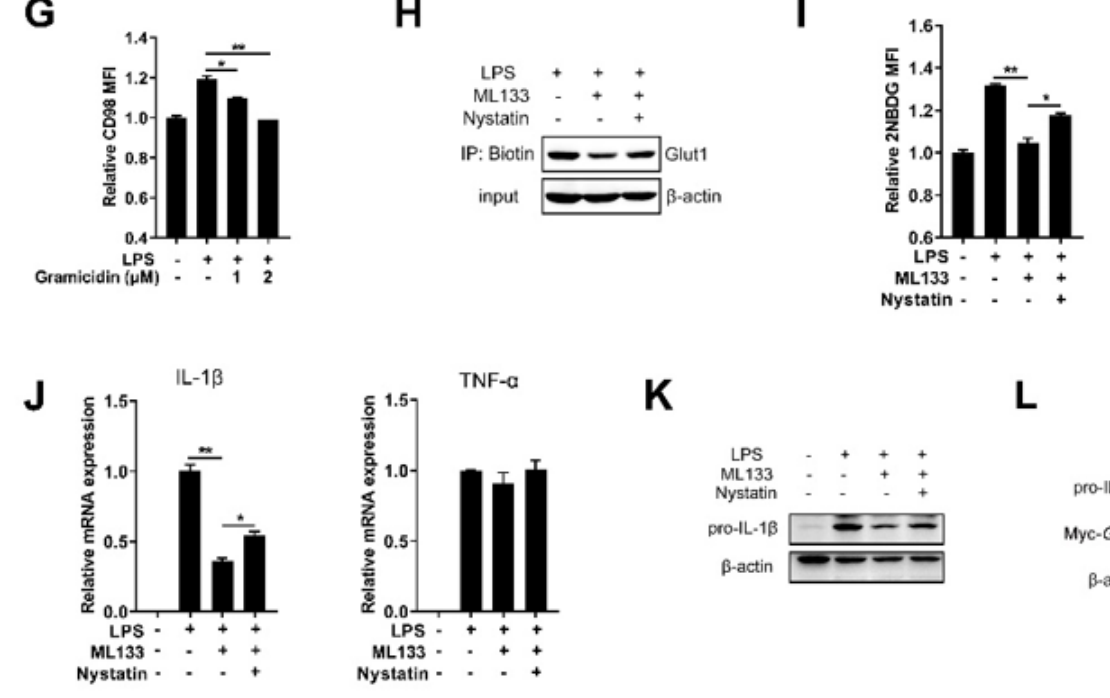

$\mathbf{K}$

$\mathbf{L}$

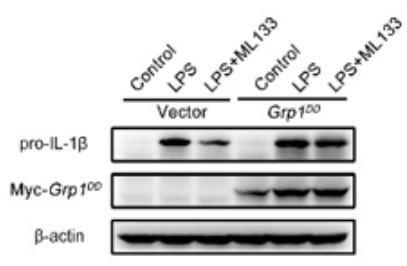

\section{Figure 7}

Kir2.1 supports nutrient supply by promoting the surface expression of nutrient transporters in LPSstimulated macrophages ( $A$ and B) KEGG pathway (A) and Reactome pathway (B) analysis of differential genes enrichments under ML133 treatment. BMDMs treated with $500 \mathrm{ng} / \mathrm{ml}$ LPS or LPS plus $25 \mu \mathrm{M}$ ML133 for $6 \mathrm{~h}$, then mRNA was extracted for RNA-sequencing. (C and D) Membrane Glut1 expression assay. Peritoneal macrophages treated with or without $500 \mathrm{ng} / \mathrm{ml}$ LPS in the presence or absence of 25 
$\mu \mathrm{M}$ ML133 (C) or $50 \mathrm{mM} \mathrm{KCl}$ (D) for $2 \mathrm{~h}$, then Membrane Glut1 expression were detected by FACS or analysis by western blot of biotinylated membrane Glut1 expression. (mean \pm SD) (E) Membrane CD 98 expression assay. Peritoneal macrophages treated with or without $500 \mathrm{ng} / \mathrm{ml}$ LPS in the presence or absence of $25 \mu \mathrm{M} \mathrm{ML} 133$ or $50 \mathrm{mM} \mathrm{KCl}$ for $2 \mathrm{~h}$ followed by FACS analysis of relative membrane CD 98 expression. (mean $\pm \mathrm{SD})(\mathrm{F})$ Membrane Glut1 expression assay. Peritoneal macrophages treated with or without $500 \mathrm{ng} / \mathrm{ml}$ LPS in the presence or absence of $2 \mu \mathrm{M}$ Gramicidin for $2 \mathrm{~h}$, then Membrane Glut1 expression were detected by FACS or analysis by western blot of biotinylated membrane Glut1 expression. (mean \pm SD) $(G)$ Membrane CD98 expression assay. Peritoneal macrophages treated with or without $500 \mathrm{ng} / \mathrm{ml}$ LPS in the presence or absence of $2 \mu \mathrm{M}$ Gramicidin for $2 \mathrm{~h}$ followed by FACS analysis of relative membrane CD98 expression. (mean $\pm \mathrm{SD})(\mathrm{H})$ Membrane Glut1 expression assay. Peritoneal macrophages treated with $500 \mathrm{ng} / \mathrm{ml}$ LPS and $25 \mu \mathrm{M} \mathrm{ML} 133$ in the presence or absence of $6 \mu \mathrm{g} / \mathrm{ml}$ Nystatin for $2 \mathrm{~h}$, then membrane Glut1 expression were detected by western blot of biotinylated membrane Glut1 expression (I) In vitro glucose uptake assay. Mouse peritoneal macrophages treated with $500 \mathrm{ng} / \mathrm{ml}$ LPS and $25 \mu \mathrm{M}$ ML133 in the presence or absence of $6 \mu \mathrm{g} / \mathrm{ml}$ Nystatin for $30 \mathrm{~min}$, then cells were subjected to glucose uptake assay (mean $\pm \mathrm{SD}$ ). ( $\mathrm{J}$ and $\mathrm{K}) \mathrm{IL}-1 \beta$ and TNF- $\alpha$ mRNA transcription (I) and pro-IL-1 $\beta$ expression (K) analysis. Mouse peritoneal macrophages were treated with $500 \mathrm{ng} / \mathrm{ml}$ LPS and $25 \mu \mathrm{M}$ ML133 in the presence or absence of $6 \mu \mathrm{g} / \mathrm{ml}$ Nystatin for $6 \mathrm{~h}$, then qPCR and western blot were performed (mean $\pm \mathrm{SD}$ ). ( $(\mathrm{L})$ Western blot of pro-IL-1 $\beta$ expression in BMDMs overexpressed with vector or Grp1DD mutant. Cells were treated with or without $500 \mathrm{ng} / \mathrm{ml}$ LPS in the presence or absence of $25 \mu \mathrm{M}$ ML133 for $6 \mathrm{~h}$ followed by western blot detection of pro-IL-1 $\beta$ expression. ${ }^{*} \mathrm{p}<0.05,{ }^{\star \star} \mathrm{p}<0.01$, ${ }^{\star \star \star} \mathrm{p}$ $<0.001$ (two-tailed unpaired Student's t-test). The qPCR data, western blot data and FACS data are representative of three independent experiments. See also Figure S7.

\section{Supplementary Files}

This is a list of supplementary files associated with this preprint. Click to download.

- Sl.docx 